\title{
Aerobic Exercise and Pharmacological Therapies for Skeletal Myopathy in Heart Failure: Similarities and Differences
}

\author{
Aline V. Bacurau, Telma F. Cunha, Rodrigo W. Souza, Vanessa A. Voltarelli, \\ Daniele Gabriel-Costa, and Patricia C. Brum
}

School of Physical Education and Sport, University of São Paulo, 05508-030 São Paulo, SP, Brazil

Correspondence should be addressed to Patricia C. Brum; pcbrum@usp.br

Received 25 July 2015; Accepted 29 September 2015

Academic Editor: Matthew C. Zimmerman

Copyright (C) 2016 Aline V. Bacurau et al. This is an open access article distributed under the Creative Commons Attribution License, which permits unrestricted use, distribution, and reproduction in any medium, provided the original work is properly cited.

\begin{abstract}
Skeletal myopathy has been identified as a major comorbidity of heart failure (HF) affecting up to $20 \%$ of ambulatory patients leading to shortness of breath, early fatigue, and exercise intolerance. Neurohumoral blockade, through the inhibition of renin angiotensin aldosterone system (RAS) and $\beta$-adrenergic receptor blockade ( $\beta$-blockers), is a mandatory pharmacological therapy of HF since it reduces symptoms, mortality, and sudden death. However, the effect of these drugs on skeletal myopathy needs to be clarified, since exercise intolerance remains in HF patients optimized with $\beta$-blockers and inhibitors of RAS. Aerobic exercise training (AET) is efficient in counteracting skeletal myopathy and in improving functional capacity and quality of life. Indeed, AET has beneficial effects on failing heart itself despite being of less magnitude compared with neurohumoral blockade. In this way, AET should be implemented in the care standards, together with pharmacological therapies. Since both neurohumoral inhibition and AET have a direct and/or indirect impact on skeletal muscle, this review aims to provide an overview of the isolated effects of these therapeutic approaches in counteracting skeletal myopathy in HF. The similarities and dissimilarities of neurohumoral inhibition and AET therapies are also discussed to identify potential advantageous effects of these combined therapies for treating HF.
\end{abstract}

\section{Introduction}

Heart failure (HF) is a significant cause of morbidity and mortality associated with high health care costs [1]. More than 20 million people worldwide are estimated to have HF, and this situation is more critical considering that the prevalence of HF will rise as the mean age of the population increases [1].

Cardiac cachexia is a serious complication of HF with a prevalence of 16-42\% [2] and associated with loss of appetite (anorexia), anemia, systemic inflammation, altered hormones, metabolic abnormalities, and skeletal myopathy. Altogether, these features lead to severe and unintentional body weight loss that occurs in cachectic states. Skeletal myopathy is one of the main features of cardiac cachexia associated with HF progression and severity. It is characterized by abnormalities in skeletal muscle structure and function that include atrophy, a shift toward fast twitch fibers, muscle metabolic dysfunction, and impaired muscle contractility that, combined, play a major role in shortness of breath, early fatigue, and exercise intolerance observed in HF [3-6].

Chronic muscle underperfusion and/or metabolic disturbance in HF lead to an overactivation of muscle afferents, such as mechano-metaboreceptors $[7,8]$, exacerbating sympathetic nervous system. Importantly, sustained sympathetic hyperactivity adversely affects muscle performance in HF by altering its metabolic status and limiting oxygen supply to exercising muscle contributing to exercise intolerance [9]. Furthermore, sustained sympathetic hyperactivity increases muscle reactive oxygen species (ROS) production (e.g., by catecholamine autooxidation and activation of nicotinamide adenine dinucleotide phosphate-oxidase-NADPH oxidase) and muscle inflammation [9-15], which contributes to skeletal myopathy in HF [10]. Altogether, these alterations will set up a vicious cycle between skeletal myopathy and progression of HF [6] being addressed as "muscle hypothesis" [16-18]. In fact, the clinical course of HF involves a continuous compensatory activation of neurohumoral systems, such as 
renin angiotensin aldosterone (RAS) system and sympathetic nervous system paralleled by parasympathetic withdrawal [19].

The understanding of $\mathrm{HF}$ as a neurohumoral disorder instead of a hemodynamic disease (throughout most of the 20th century) has driven changes in the mandatory pharmacological therapy of HF. In this sense, inhibition of the RAS and $\beta$-adrenergic receptor antagonists ( $\beta$-blockers) has gained strength in HF therapy reducing symptoms, mortality, and sudden death. However, the impact of these drugs on skeletal myopathy needs to be clarified, since HF patients optimized with $\beta$-blockers and inhibitors of RAS still display, to certain degree, skeletal myopathy and exercise intolerance.

It is widely recognized that aerobic exercise training (AET) is an efficient nonpharmacologic therapy for HF that improves quality of life and exercise tolerance; the latter associated with remarkable attenuation of skeletal myopathy. In fact, AET counteracts systemic and local inflammation, neurohumoral exacerbation, and increased oxidative stress, which contribute to skeletal myopathy in HF [20-28]. However, the mechanisms underlying the benefits of AET in counteracting skeletal myopathy are a topic of major interest under current investigation.

Since both pharmacological and nonpharmacological therapies have a direct and/or indirect impact on skeletal myopathy, this review aims to provide an overview of these therapeutic approaches in counteracting skeletal myopathy in HF.

\section{Impact of Neurohumoral Blockade in HF-Induced Skeletal Myopathy}

Sustained sympathetic hyperactivity and RAS activation are commonly associated with the pathogenesis of HF [6]. Despite the changes in cardiac tissue being causal and major in HF, skeletal muscle abnormalities are also affected by neurohumoral overactivation. Even though the beneficial effect of neurohumoral blockade on cardiac muscle is undeniable, there is paucity of data about its effects on skeletal myopathy.

In this section, we will discuss the impact of $\beta$-blockers and RAS inhibition on skeletal myopathy considering their potential direct and/or indirect effects.

2.1. $\beta$-Adrenergic Receptor Signaling in Skeletal Muscle: Effects of $\beta$-Blockade in HF. Sympathetic hyperactivity is a hallmark of $\mathrm{HF}$ associated with poor prognosis being an independent predictor of mortality [6]. Over the last few years, our group has demonstrated that sympathetic hyperactivity contributes to skeletal myopathy in a mouse model of $\mathrm{HF}$ and in patients with $\operatorname{HF}[15,20,29]$.

In skeletal muscle, the sympathetic activity is mediated by $\beta$-adrenergic receptors ( $\beta$-AR). These adrenergic receptors are expressed on the membrane of skeletal muscle cells in a proportion of $90: 10$ for subtypes $\beta_{2}$-AR and $\beta_{1}$-AR, respectively [30-32]. Some studies suggest that $\beta_{3}$-AR subtype can also be expressed in skeletal muscle, in a smaller percentage $[33,34]$.

The $\beta$-AR density in skeletal muscle can be different depending on the fiber type predominance. Type I fibers express two to three times more $\beta$-AR than type II fibers
[35-37], which corroborates the highest density of $\beta_{1}$-ARs and $\beta_{2}$-ARs in oxidative skeletal muscles when compared to glycolytic ones [32, 37-40]. In fact, Jensen et al. [41] observed that rat soleus muscle (predominantly oxidative metabolism and mainly comprised with type I fibers) has a higher density of $\beta$-ARs than white gastrocnemius (mainly comprised with type II fibers). However, the functional significance of this difference in $\beta$-AR density between oxidative and glycolytic muscles has not been fully understood, since the $\beta$-AR responsiveness to $\beta$-agonists appears to be greater in glycolytic than oxidative muscles [38, 42].

Even though the acute and chronic effects of sympathetic activation in skeletal muscle are well known, the role played by sympathetic overactivation in skeletal muscle associated with chronic diseases, such as HF, needs to be better clarified. In this sense, direct acute effects of $\beta_{2}$-AR activation in skeletal muscle include increased lipolysis $[43,44]$, glycogenolysis $[45,46]$, glucose uptake $[47,48]$, and increased contractility $[49,50]$. Furthermore, $\beta_{2}$-AR activation has recently emerged as a potential signaling pathway involved in mitochondrial function, biogenesis, and dynamics in skeletal muscle and in other tissues [51-60] (Figure 1). Different from acute $\beta_{2}$-AR activation, the response of skeletal muscle to chronic $\beta_{2}-\mathrm{AR}$ activation leads to decreased apoptosis [61], improved muscle regeneration [62], increased skeletal muscle strength, a shift toward type II glycolytic fibers, and a pronounced increase in skeletal muscle mass [63-65] (Figure 1). In fact, chronic activation of $\beta_{2}$-ARs leading to skeletal muscle hypertrophy is well described in several studies using $\beta$-AR agonists, such as clenbuterol, formoterol (selective $\beta_{2}$-AR agonists), and isoproterenol (a nonselective $\beta$-AR agonist) administration in healthy and atrophic animals [58, 61, 64-67]. Although the signaling pathways responsible for these muscle anabolic effects of chronic $\beta_{2}$-AR activation are poorly understood, they have been associated with an inhibition of proteolysis (calcium-dependent proteolysis and ATP dependent proteolysis) and an activation of protein synthesis signaling pathways (mainly protein kinase B-Akt/mammalian target of rapamycin-mTOR signaling pathway) $[58,65,68,69]$.

Considering the hypertrophic effects of chronic $\beta$-AR activation, some authors have suggested $\beta$-AR agonists as a pharmacologic therapy in counteracting cardiac cachexia in late 80 's decade onwards. Although these studies have observed some direct beneficial effects of $\beta$-AR agonists on muscle mass in $\mathrm{HF}$, tachycardia was reported as a main side effect [70]. This might be due to the $\beta_{1}$-AR related cardiac effect, and the use of specific $\beta_{2}$-AR agonists would be more efficient in counteracting, at least, some features of cardiac cachexia [71]. In fact, we have observed that mice lacking $\beta_{2}$-AR display more pronounced exercise intolerance and a more severe skeletal muscle atrophy after HF induced by myocardial infarction when compared with control mice [72]. Therefore, it is possible that, in early stages of the cardiac disease, increased sympathetic activity through the activation of $\beta_{2}$-AR could be able to delay the onset of muscle proteolysis. This seems to be the case in our mice model of sympathetic hyperactivity induced HF. At 3 months of age, these mice display increased sympathetic activity with no signs of HF associated with plantaris hypertrophy [29]. 


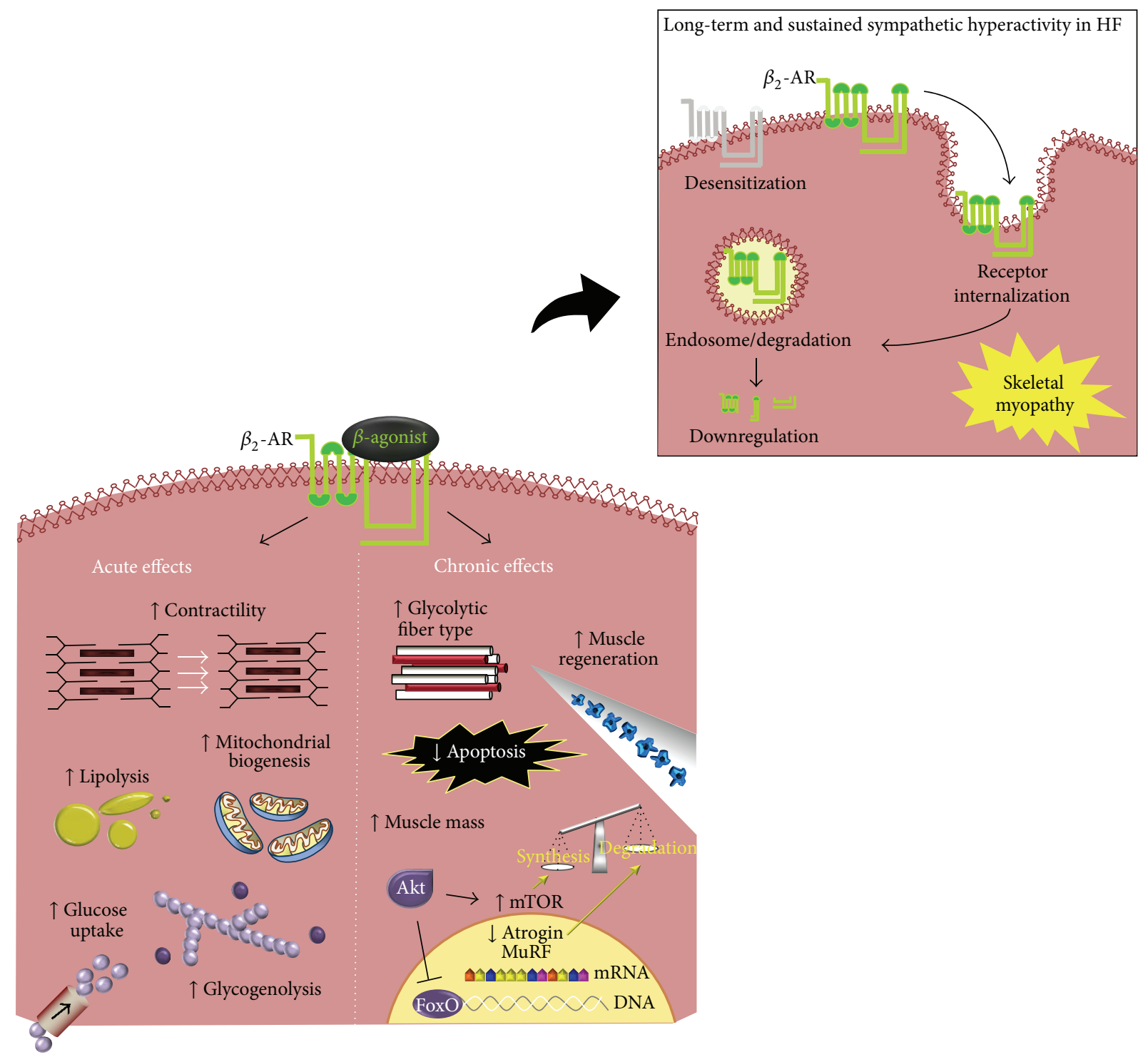

FIGURE 1: Effects of $\beta$-adrenergic receptor activation in skeletal muscle. In skeletal muscle, sympathetic activity is mediated mainly by $\beta_{2}$-adrenergic receptors $\left(\beta_{2}\right.$-ARs) and leads to beneficial acute and chronic effects on muscle metabolism, function, and mass. In this sense, keeping $\beta_{2}$-ARs signaling in early stage HF might be reasonable since it can delay skeletal myopathy. In contrast, long-term and sustained sympathetic hyperactivity (figure inset) in severe heart failure exerts toxic effects on skeletal muscles leading to $\beta_{2}$-AR desensitization/downregulation and loss of function, which will further aggravate skeletal myopathy. In this case, the use of selective (acting on $\beta_{1}$-AR) versus nonselective (acting on both $\beta_{1}$-AR and $\beta_{2}$-AR) $\beta$-blockers to counteract skeletal myopathy needs further investigation. Akt: protein kinase B, Atrogin-1/MAFbx: muscle atrophy F-box protein, MuRF-1: muscle RING-finger protein-1, FoxO: forkhead family of transcription factors, and mTOR: mammalian target of rapamycin.

This hypertrophic response is mediated by $\beta_{2}$-AR activation since mice lacking $\beta_{2}$-AR display no hypertrophic response to chronic isoproterenol delivery (15 days) [29]. It is of interest that when sympathetic hyperactivity persists and HF aggravates in our mice model, plantaris atrophy and skeletal myopathy are observed [72]. Therefore, while acute and chronic activation of $\beta_{2}$-AR by $\beta_{2}$-agonists seems to counteract skeletal myopathy in early stages of the disease, long-term and sustained activation of $\beta_{2}$-AR aggravates skeletal myopathy in HF, which might be related to $\beta_{2}$ AR desensitization and downregulation reducing its anabolic effects.
Studies have shown that $\beta_{2}$-ARs are able to internalize into the cytoplasm of skeletal muscle cell after their activation with $\beta_{2}$-AR agonists. Rothwell et al. [73] demonstrated that prolonged clenbuterol treatment reduces by $65 \%$ the density of $\beta_{2}$-AR in skeletal muscle, which suggests receptor internalization and further downregulation. Jensen et al. [41] also showed that $50 \%$ of $\beta_{2}$-ARs undergo internalization in skeletal muscle after 30 minutes of isoproterenol treatment. Additionally, $80 \%$ of the internalized receptor recycles, returning to the cell membrane. However, it is not clear whether the sensitivity of recycled receptors to the agonist is preserved or not. Therefore, these data highlight 
the differences in skeletal muscle response to short-term and long-term/sustained $\beta_{2}$-AR stimulation as aforementioned. This is of particular importance if one considers that longterm sustained activation of $\beta_{2}$-AR by sympathetic hyperactivity in HF might lead to $\beta_{2}$-AR downregulation and loss of function, which will further aggravate skeletal myopathy in HF. Indeed, more studies are needed to test whether the usage of nonselective $\beta$-blockers (blocking $\beta_{2}$-AR in skeletal muscle) in HF therapy would be beneficial or detrimental to counteract skeletal myopathy.

\subsection{Role of Renin Angiotensin Aldosterone System in Skeletal} Muscle: Effects of Its Inhibition in HF. The inhibition of RAS has been demonstrated as an effective pharmacological therapy in HF. The beneficial effects of RAS inhibition in $\mathrm{HF}$ include improved clinical status and quality of life and survival paralleled by reduction in neurohumoral activation and hospitalization [74-76].

Angiotensin II (Ang II), the main effector molecule of the RAS (canonical axis), is processed by angiotensin converting enzyme (ACE) from inactive angiotensin I, which is responsible for vasoconstriction, proliferation, and proinflammatory effects [77]. Increased Ang II is a hallmark of HF, and the clinical use of $\mathrm{ACE}$ inhibitor or $\mathrm{AT}_{1}$ receptor blockade is an obligatory HF therapy, reducing both systemic and local RAS deleterious effects on cardiovascular system [78]. It is of interest that ACE inhibition attenuates body weight loss associated with impaired survival in HF patients [79]. Taking into consideration that body weight loss in HF is also associated with skeletal muscle atrophy $[5,80,81]$, the attenuated body weight loss by ACE inhibitors in HF might be due to a reduced loss of muscle mass.

Several studies have demonstrated a detrimental role of Ang II in skeletal muscle, either independently or combined with the systemic RAS activation $[82,83]$. A pioneer study by Brink and coworkers showed that Ang II infusion by osmotic minipumps in rats induces a significant body weight loss through a reduction of food intake and decreased circulating insulin-like growth factor-I (IGF-I), which are completely prevented by losartan treatment ( $\mathrm{AT}_{1}$ receptor blocker) [84]. In fact, Ang II leads to muscle wasting inducing protein breakdown and decreasing IGF-I signaling in skeletal muscle [85-87]. To further confirm the role of Ang II in IGF-I signaling in skeletal muscle, specific overexpression of IGF-I (MLC/mIGF-I mice) is able to inhibit Ang II-induced skeletal muscle wasting through activation of Akt/FoxO (forkhead box O) pathway and inhibition of E3 ubiquitin ligase Atrogin1/MAFbx mRNA levels [88-91].

Besides its effects on muscle tissue, Ang II inhibits skeletal muscle stem (satellite) cell proliferation, leading to reduced muscle regenerative capacity [92]. In fact, $\mathrm{AT}_{1}$ receptor is highly expressed in satellite cells and its activation leads to depleted basal pool of satellite cells, which is blunted by $\mathrm{AT}_{1}$ receptor blockade [92]. Even though little is known about the skeletal muscle regenerative capacity in HFinduced muscle wasting, another atrophic state, such as aging sarcopenia (muscle wasting with aging), is associated with a reduced skeletal muscle regenerative capacity associated with a decline in satellite cell function and/or number [93]. Thus,
Ang II-mediated inhibition of skeletal muscle regeneration may play a significant role in muscle wasting induced by chronic diseases, such as HF. Therefore, future studies should be addressed to test whether Ang II would induce a potential deficit of skeletal muscle regeneration in HF. Indeed, the effects of RAS inhibition on satellite cells function and number in HF have not been addressed so far.

In addition to Ang II direct effects on skeletal muscle and muscle satellite cells, indirect effects of Ang II regulating circulating hormones, cytokines, and metabolic effectors besides ROS formation also affect muscle wasting. The AMPactivated protein kinase (AMPK) is a key regulator of energy status acting as a metabolic energy sensor modulating glucose and lipid metabolism. Ang II blocks AMPK activity and reduces muscle mass [94]. Conversely, AMPK activation by AICAR reverses Ang II-mediated increased E3 ubiquitin ligases mRNA levels [93]. Other indirect effects of Ang II in skeletal muscle are activation of glucocorticoid-induced muscle breakdown [88] and NADPH oxidase induced ROS formation in skeletal muscle [11, 94-96]. In fact, Ang IIinduced muscle wasting was inhibited by NADPH oxidase subunit in p47phox deficient mice [91]. Finally, Ang II increases interleukin-6 (IL-6) cytokine levels leading to an imbalance in protein synthesis : degradation ratio by inhibiting IGF-I/Akt/mTOR signaling while activating ubiquitinproteasome system (UPS) and caspase-3 promoting muscle wasting [97].

Considering that Ang II plays a role in weight body loss and muscle wasting in HF [79], ACE inhibitors are recommended to partially counteract these effects [98]. Indeed, pharmacological therapy with RAS inhibition in HF patients increases exercise tolerance and quality of life, which might be related to an attenuated skeletal myopathy $[99,100]$. In fact, HF treatment with perindopril (ACE inhibitor) increases respiratory muscle strength in humans [101] and partially prevents skeletal muscle dysfunction induced by myocardial infarction in rats [102]. The same has been observed for $\mathrm{AT}_{1}$ receptor antagonists attenuating, at least in part, HFinduced reduced skeletal muscle force. Telmisartan increases muscle force generation and endurance performance by activation of peroxisome proliferator-activated receptor gamma$(\mathrm{PPAR} \delta$-) AMPK signaling in transgenic mice [103]. Azilsartan medoxomil, a new $\mathrm{AT}_{1}$ receptor antagonist, induces Akt phosphorylation and glucose uptake in Sprague-Dawley rats [104]. Irbesartan protects tibial muscle from apoptosisdependent atrophy in monocrotaline HF model. In myocardial infarcted mice, muscle wasting paralleled by reduced satellite cells numbers is partially inhibited by candesartan treatment [92].

Another important effector of canonical RAS axis activation is the aldosterone, which is also involved in muscle atrophy in HF $[105,106]$. Interestingly, spironolactone administration (a mineralocorticoid antagonist) decreased skeletal muscle apoptosis and increased muscle contractility, improving exercise capacity [107]. Therefore, these data provide evidence for a pivotal role of aldosterone in inducing muscle atrophy in $\mathrm{HF}$ and mineralocorticoid antagonism as a potential therapy for counteracting skeletal myopathy. 
It is important to highlight the complexity of RAS on skeletal muscle mass regulation, since there is a paradoxical "protective arm" in RAS system. While the most deleterious effects of Ang II-induced muscle wasting are mediated via $\mathrm{AT}_{1}$ receptors, $\mathrm{AT}_{2}$ receptor triggers beneficial effects on muscle regeneration in both in vivo and in vitro models [108]. Indeed, $\mathrm{AT}_{2}$ receptor antagonist reduces regenerating myofiber size and myoblast differentiation marker (e.g., myogenin and embryonic myosin heavy chain, eMHC) mRNA levels [108].

A noncanonical protective axis of RAS involves the peptide Ang-(1-7). Ang-(1-7) is synthesized directly from Ang II or indirectly from Ang I by an ACE homolog enzyme (ACE2), which in turn binds into the Mas receptor $[109,110]$. ACE2 is expressed uniformly within soleus and plantaris muscles [111]. The endogenous RAS axis has opposite effects, when compared to the classical signaling pathway. It triggers vasodilation and improves skeletal muscle metabolism, preventing the fibrosis and apoptosis processes $[109,112]$.

Taken together, pharmacological therapy with inhibitors of RAS (canonical axis) has demonstrated some positive outcomes in skeletal myopathy of HF patients, such as a partial attenuation in exercise intolerance and muscle wasting. The relative contribution of direct versus indirect beneficial effects of RAS inhibition on skeletal myopathy in HF remains unclear. This seems to be (canonical axis) direct and indirect effects on skeletal muscle as can be seen in Figure 2. In parallel, therapies that increase RAS noncanonical axis, such as ACE2 and Ang-(1-7), are also of great clinical relevance for attenuating skeletal myopathy in HF. In this sense, AET has emerged as a potential therapy modulating both canonical and noncanonical axis of RAS (for details, see Section 3.2).

\section{Impact of Aerobic Exercise \\ Training on Counteracting HF-Induced Skeletal Myopathy}

AET has been recognized as an efficient and safe preventive and therapeutic strategy for cardiovascular diseases $[113,114]$, as it reduces a number of cardiovascular risk factors [115, 116] and improves peak oxygen uptake (peak $\mathrm{VO}_{2}$ ), exercise tolerance, and quality of life $[25,117]$. Indeed, both European [118] and American [119] guidelines have agreed upon the recommendation of AET for all stable outpatients, in addition to optimal pharmacological therapy. Several beneficial effects of AET on HF have been demonstrated in heart, endothelium, and skeletal muscle to name a few [120]. It is worth mentioning that the responsiveness of skeletal muscle to AET is far higher than that to pharmacological therapy, which highlights AET as a potent strategy to counteract skeletal myopathy in HF. Indeed, the impact of AET on skeletal muscle is related to several aspects of muscle function as it improves metabolic and contractile properties besides attenuating muscle wasting, as we are going to discuss below.

3.1. Muscle Metabolic and Contractile Responses. Skeletal myopathy leads to several muscle metabolic changes in human and animal HF [121-128], such as a switch toward type II glycolytic fibers and decreased mitochondrial density and function (e.g., decreased cytochrome oxidase activity and other oxidative enzymes). Altogether, these changes trigger a reduced aerobic capacity and exercise intolerance $[121,123$, $125,128]$. In fact, HF patients display delayed availability of phosphocreatine during exercise, anticipating muscle fatigue [124]. Indeed, a decrease in protein expression of a potent regulator of mitochondrial biogenesis, PGC- $1 \alpha$ (i.e., peroxisome proliferator-activated receptor gamma), is observed in rat $\mathrm{HF}[122,126,127]$. These metabolic changes in skeletal muscle contribute to increased muscle fatigability and lactate accumulation during exercise in $\mathrm{HF}$.

AET has been considered an effective strategy in modulating muscle metabolic changes induced by HF. In fact, AET increases peak $\mathrm{VO}_{2}$ and exercise tolerance, which is related to energy production and utilization efficacy. Regarding substrate supply, AET increases muscle phosphocreatine availability and resynthesis [129, 130]. Indeed, muscle ATP levels are increased by AET due to improved oxidative enzyme activities and increased mitochondrial content. These improvements in muscle substrate supply and uptake are optimized by the enhanced blood supply to skeletal muscle, as AET prevents HF-induced capillary rarefaction and endothelial dysfunction [125, 131-133]. Additionally, AET promotes a "reshift" toward more oxidative type I fibers, which are more resistant to muscle fatigue $[29,134]$.

Another important change induced by HF is a significant impaired muscle contractility associated with changes in $\mathrm{Ca}^{2+}$ handling, which will further affect muscle strength and resistance to fatigue. In this sense, $\mathrm{HF}$ in rats decreases skeletal muscle sarcoplasmic $\mathrm{Ca}^{2+}$ levels associated with reduced rate of sarcoplasmic reticulum $\mathrm{Ca}^{2+}$ release [135] and reuptake [123]. These findings are extended to human HF by Middlekauff et al. [136], who verified reduced $\mathrm{Ca}^{2+}$ release and reuptake associated with decreased dihydropyridine receptors and sarco(endo)plasmic reticulum $\mathrm{Ca}^{2+}$-ATPase (SERCA) 2a protein expression in vastus lateralis of $\mathrm{HF}$ patients.

AET improves skeletal muscle $\mathrm{Ca}^{2+}$ handling. We have previously demonstrated that AET improves the net balance of $\mathrm{Ca}^{2+}$ handling proteins in $\mathrm{HF}$ mice involved in sarcoplasmic $\mathrm{Ca}^{2+}$ release and reuptake in soleus and plantaris muscles leading to improved skeletal muscle function [137]. Interestingly, endurance leg extension training also reduces $\mathrm{Ca}^{2+}$ leaking by ryanodine receptors in vastus lateralis of $\mathrm{HF}$ patients [138].

Taken together, data from the literature provide evidence for AET as a strategy of paramount importance to prevent muscle metabolic and contractile dysfunction in HF.

3.2. Neurohumoral and Muscle Mass Regulation. Skeletal muscle loss is considered an independent predictor of morbidity and mortality in HF patients [139]. In fact, muscle wasting is triggered by neurohumoral overactivation and increased proinflammatory cytokines [27, 140, 141] being associated with impaired strength and peak $\mathrm{VO}_{2}[139,142]$. So far, no specific treatment is available for muscle wasting in HF. Therefore, adjuvant nonpharmacological therapies as 


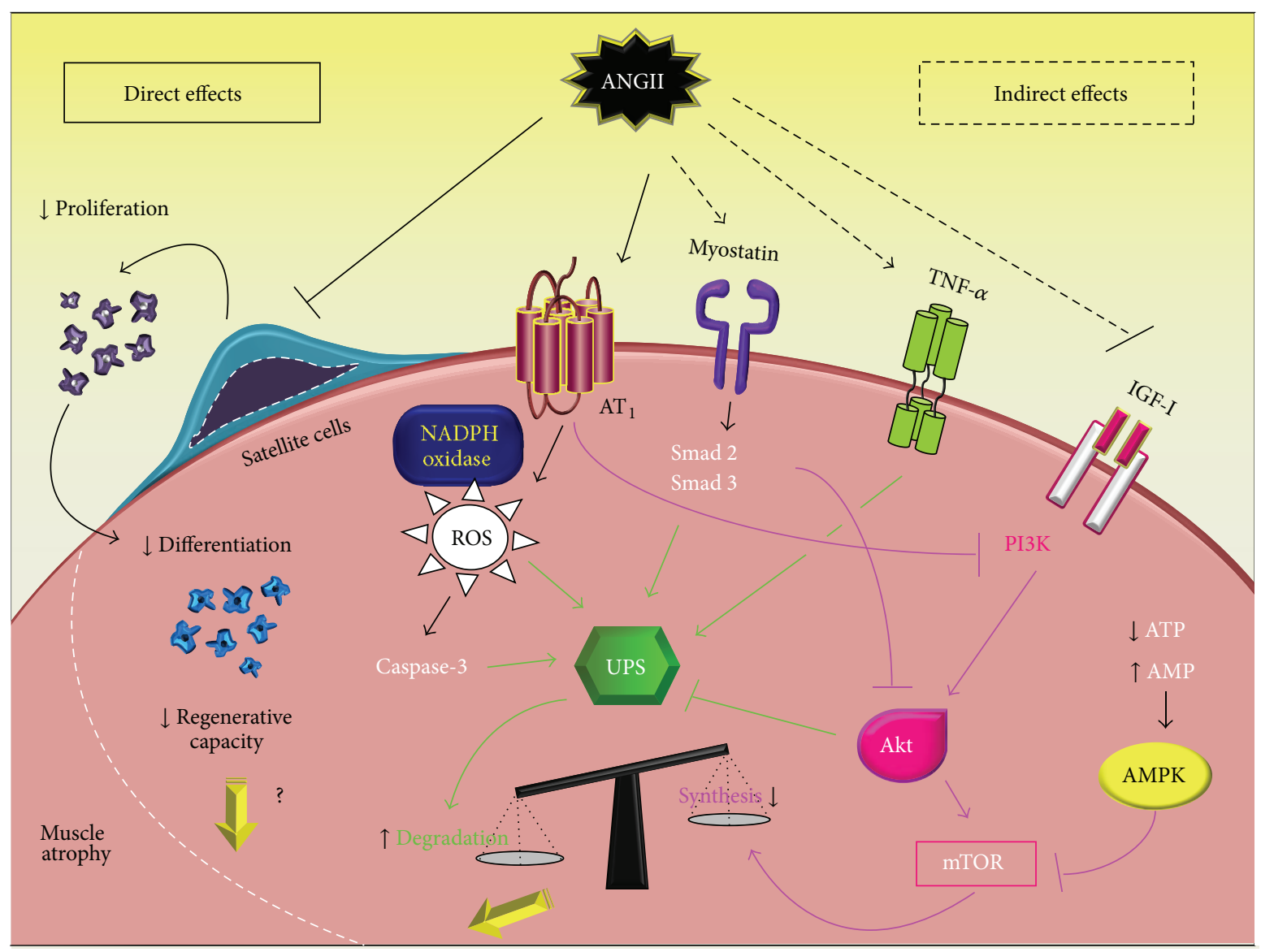

Figure 2: Direct and indirect effects of Ang II on skeletal muscle mass. The direct effects of angiotensin II (Ang II) in skeletal muscle include increases ROS production via $\mathrm{AT}_{1}$ receptor and NADPH oxidase activation, which results in activation of UPS and protein degradation. The indirect effects of systemic Ang II are mediated by increased ROS induced caspase- 3 besides enhanced TNF- $\alpha$ and myostatin levels. Ang II also directly suppresses protein synthesis via $\mathrm{AT}_{1}$ receptor inhibiting PI3K and by indirect mechanisms via Ang II attenuating IGFI while increasing myostatin levels. Ang II-induced muscle wasting can also result from impaired muscle regeneration by Ang II-induced inhibition of skeletal muscle stem (satellite) cell proliferation and function. It is important to highlight that these multiple direct and indirect mechanisms involving Ang II-induced muscle wasting are potential mediators of cardiac cachexia. PI3K: phosphoinositide 3-kinase, Akt: protein kinase B, UPS: ubiquitin-proteasome system, mTOR: mammalian target of rapamycin, TNF- $\alpha$ : tumor necrosis factor-alpha, IGF-I: insulin-like growth factor-I, ATP: adenosine triphosphate, AMP: adenosine monophosphate, AMPK: AMP-activated protein kinase, NADPH oxidase: nicotinamide adenine dinucleotide phosphate-oxidase, and ROS: reactive oxygen species.

nutritional supplementation and AET have been encouraged. Indeed, AET is efficient in counteracting skeletal myopathy in $\mathrm{HF}$ by improving skeletal muscle function (direct effect) or by attenuating cardiac dysfunction and neurohumoral hyperactivity (indirect effect).

Regarding neurohumoral overactivation, AET reduces muscle sympathetic nerve activity, which is associated with an improved clinical outcome [24, 25]. In fact, Roveda et al. [25] have demonstrated that a 4-month period of moderate AET leads to a significant reduction in muscle sympathetic nerve activity in HF patients, returning to the values of age-matched healthy controls. The mechanisms underlying the reduction in sympathetic hyperactivation by AET are still a topic under current investigation. The potential candidates underlying the reduced sympathetic nerve activity by AET include afferent autonomic control coordinated by arterial baroreceptors, cardiopulmonary receptors, ergoreceptors, and chemoreceptors [143-145]. AET can improve muscle metaboreflex and mechanoreflex control of muscle sympathetic nerve activity in HF animal models and human HF [146-148]. In fact, we have recently observed that AET improves metaboreflex and mechanoreflex associated with changes in cyclooxygenase pathway [149]. Indeed, AET plays an important role in the control of cardiovascular reflexes by the central nervous system. In this sense, AET seems to modulate projections arising from hypothalamic paraventricular nucleus (mainly, peptidergic hypothalamic preautonomic neurons) that converge to nucleus tractus solitarii [147]. Additionally, reduced $\mathrm{AT}_{1}$ receptors of angiotensin II in nucleus tractus solitarii and normalized ACE and ACE2 levels in the brain of $\mathrm{HF}$ animal models have been proposed as major mechanisms of reducing sympathetic activity by AET $[148,150]$.

AET reduces circulating catecholamine levels in both HF patients and animal models [26, 27]. AET improves capillary density and muscle redox balance in a sympathetic 
hyperactivity induced HF mice model [20, 29]. This is of particular interest, since sympathetic hyperactivity directly affects skeletal muscle $[29,137]$ promoting redox imbalance $[7,151]$, chronic vasoconstriction $[14,15]$, and increased muscle norepinephrine and proinflammatory cytokine levels $[140,141]$.

RAS hyperactivity is also involved in skeletal myopathy in HF primarily by activation of Ang II, increasing ROS generation, protein degradation, and apoptosis as aforementioned in Section 2.2. Interestingly, we have previously demonstrated that AET reduces serum Ang II levels besides increasing muscle Ang-(1-7), Ang-(1-7)/Ang II ratio, and Mas receptor gene expression [28]. Additionally, reduced serum Ang II levels were related to decreased sympathetic activity in HF, favoring the redox balance [7].

Neurohumoral overactivation is also associated with increased circulating/muscle proinflammatory cytokine concentrations and muscle redox imbalance, which are directly involved in muscle catabolism. In fact, increased circulating TNF- $\alpha$ levels (a proinflammatory cytokine) are observed in patients with reduced skeletal muscle cross-sectional area and muscle weakness [152]. Moreover, the increased muscle TNF$\alpha$ expression contributes to the local protein degradation, worsening muscle function and metabolism. The effects of TNF- $\alpha$ on HF-related skeletal myopathy are mediated through the activation of a family of transcription factors known as nuclear factor kappa $\mathrm{B}(\mathrm{NF}-\kappa \mathrm{B})$, which regulate UPS [153]. NF- $\kappa$ B activation leads to increased expression of the E3 ubiquitin ligases MuRF-1 and Atrogin-1 [153] and muscle proteolysis, leading to atrophy. Interestingly, AET reduces serum TNF- $\alpha$ levels [22] and plasma inflammatory markers (e.g., soluble cell adhesion molecule-1, soluble vascular cell molecule-1, and macrophage chemoattractant) [154] in trained HF patients. This response is paralleled by reduced muscle atrophy and improved muscle strength. Indeed, AET also reduces muscle expression of proinflammatory cytokines in human HF [23] while preventing TNF- $\alpha$ mediated diaphragmatic weakness in mice [155].

Increased TNF- $\alpha$ levels in HF triggers an increase in ROS production [156], which will ultimately lead to protein degradation by the UPS $[157,158]$. We have observed that AET reduces moderate (lipid hydroperoxidation) and severe (carbonylated proteins) muscle oxidative stress markers and restores antioxidant activity (e.g., superoxide dismutase) in exercise trained HF animals and patients [20, 29, 159]. Interestingly, we have observed HF-induced NADPH oxidase hyperactivity, an important source of superoxide in skeletal muscle [11]. Such hyperactivity displayed a positive correlation with muscle atrophy and increased UPS activity.

UPS is considered the main proteolytic system responsible for disposal of damaged proteins in skeletal muscle [160], which is upregulated in HF $[20,161]$. Indeed, several studies have demonstrated that skeletal muscle atrophy is mediated by the UPS overactivation [162, 163]. Although the UPS involves the concerted actions of many proteins, the key enzyme in this system is E3 (ubiquitin ligase), which couples activated ubiquitin with lysine residues on protein substrates and confers specificity to the system [158, 164]. Two muscle-specific E3 ubiquitin ligases, Atrogin-1 and
MuRF-1, are increased transcriptionally in skeletal muscle under various atrophying conditions including HF $[161,164-$ 166], making them excellent markers of muscle atrophy [167]. In contrast, AET reduces Atrogin-1 mRNA levels and proteasome activity, in animal and human HF, being an efficient strategy to prevent UPS overactivation induced by HF $[21,159,168]$. Additionally, Souza et al. [126] observed that AET by increasing muscle PGC- $1 \alpha$ expression levels prevented Atrogin-1 and MuRF-1 upregulation in an aortic stenosis model of HF rats, reinforcing the anticatabolic effect associated with increased muscle PGC-1 $\alpha$ levels [169].

Besides protein degradation, protein synthesis also plays an essential role in maintaining muscle mass [170]. Several signaling pathways are involved in protein synthesis, such as IGF-I/Akt/mTOR. In fact, IGF-I muscle levels are reduced in human HF [171]. Therefore, activation of the IGF-I/Akt/mTOR signaling pathway can be considered a good strategy to counteract HF-induced muscle wasting and cardiac cachexia. Muscle-specific IGF-I transgene expression or gene transfer in hindlimb muscles sustains muscle hypertrophy [172] and prevents muscle wasting in rodent models of muscle atrophy including Duchenne muscular dystrophy [173], dexamethasone injection [174], cast immobilization [175], Ang II infusion [88], and chronic HF [176]. Furthermore, another strategy to increase the expression of the gene encoding IGF-I is through AET $[177,178]$, which attenuates the reduced muscle IGF-I expression in HF patients $[176,179]$.

Altogether, these results suggest that AET reestablishes skeletal muscle homeostasis attenuating muscle wasting. This is crucial since muscle wasting in $\mathrm{HF}$ is related to a poor prognosis and reduced quality of life [139].

This seems to be AET effects on skeletal muscle in HF as can be seen in Figure 3.

\section{Similarities and Differences between Aerobic Exercise Training and Neurohumoral Blockade in HF-Induced Skeletal Myopathy}

Over the last few decades, the therapeutic approach most commonly used in HF has been the neurohumoral blockade, which is currently mandatory [180]. $\beta$-blockers and RAS inhibitors improve cardiac function, trigger reverse remodeling, and are directly related to reduced morbidity and mortality [181]. Furthermore, these drugs cause systemic effects, such as reduced inflammatory response and oxidative stress contributing to both cardiac and skeletal muscle improvements [76, 93, 181, 182]. These systemic effects could minimize the impairments caused by HF in skeletal muscle, improving muscle mass regulation, metabolism, and function. However, the effects of a neurohumoral blockade on skeletal muscle are still controversial, as already discussed in Section 2.1. The blockade of $\beta$-AR modifies the skeletal muscle metabolism and impairs exercise tolerance, resulting in increased perceived exertion, lower $\mathrm{VO}_{2} \mathrm{max}$, and work rate in hypertensive as well as in healthy individuals [183185]. These responses have been mainly associated with pharmacological properties of different generations of $\beta$-blockers. 


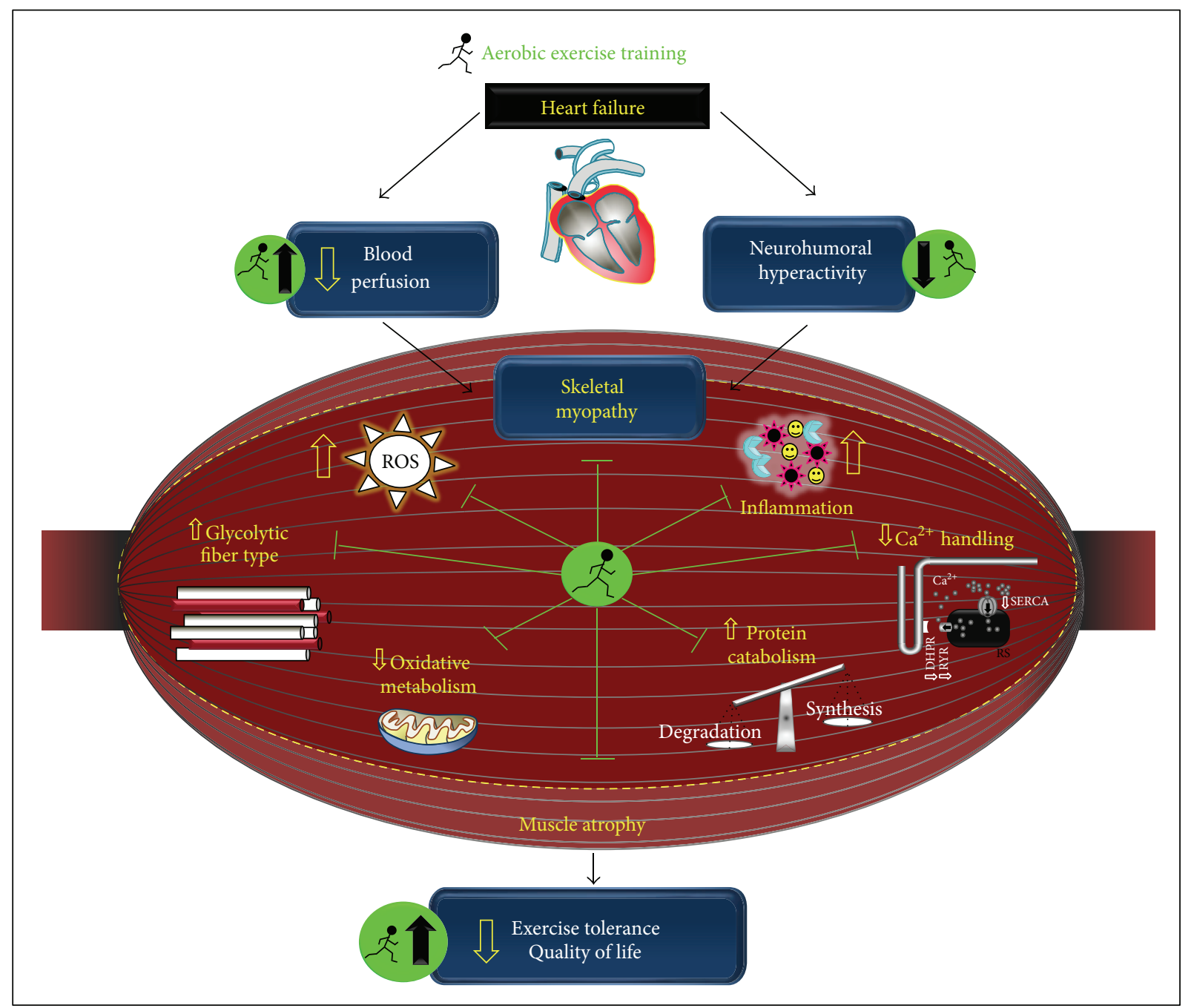

FIGURE 3: Effects of aerobic exercise training in counteracting heart failure-induced skeletal myopathy. Neurohumoral hyperactivity and reduced blood perfusion associated with heart failure contribute to skeletal myopathy, which is characterized by muscle prooxidant and inflammatory state associated with muscle contractile dysfunction and atrophy, exercise intolerance, and reduced quality of life. These responses are associated with impaired $\mathrm{Ca}^{2+}$ handling, reduced protein synthesis paralleled by increased proteolysis. Note that aerobic exercise training counteracts most of the features involved in skeletal myopathy (illustrated by filled arrows and $\perp$ ). ROS: reactive oxygen species, RYR: ryanodine receptor, DHPR: dihydropyridine receptor, and SERCA: sarcoplasmic reticulum $\mathrm{Ca}^{2+}$ ATPase.

Nonselective $\beta$-blockers, which also antagonize $\beta_{2}$-AR, may worsen these effects even more [186, 187]. Nevertheless, nebivolol, which possesses vasodilative properties mediated by NO production, does not impair exercise capacity in healthy individuals $[186,188]$. Indeed, Dalla Libera et al. [189] verified a decreased apoptosis and proinflammatory cytokines, preventing fiber shift and protein oxidation in skeletal muscle of HF rats treated with nebivolol. These positive changes could produce a favorable impact on exercise capacity and skeletal myopathy in humans [189].

RAS has also been inhibited to minimize the neurohumoral overactivation and improve cardiac function in HF. Moreover, ACE inhibitors have been associated with beneficial effects on skeletal muscle, such as improved muscle glucose uptake and mitochondrial function and a modulation of IGF-I, which is related to skeletal muscle trophicity [102,
190]. Additionally, in hypertensive patients treated with ACE inhibitors, an increased skeletal muscle cross-sectional area and a slower decline in walking speed are observed when compared to patients under other antihypertensives [99]. Another study [100] observed a smaller reduction in muscle strength and improved quality of life in elderly patients submitted to an ACE inhibitor treatment. Despite these results, it is not possible to affirm that these effects would revert skeletal myopathy in HF. Indeed, whether ACE inhibitor responses are a result of a direct effect on skeletal muscle or secondary to systemic changes (improved cardiac function and reduced proinflammatory cytokines and oxidative stress) remains to be determined.

AET has been considered the most effective strategy to counteract skeletal myopathy in HF. As aforementioned, AET improves several aspects involved in skeletal muscle function 


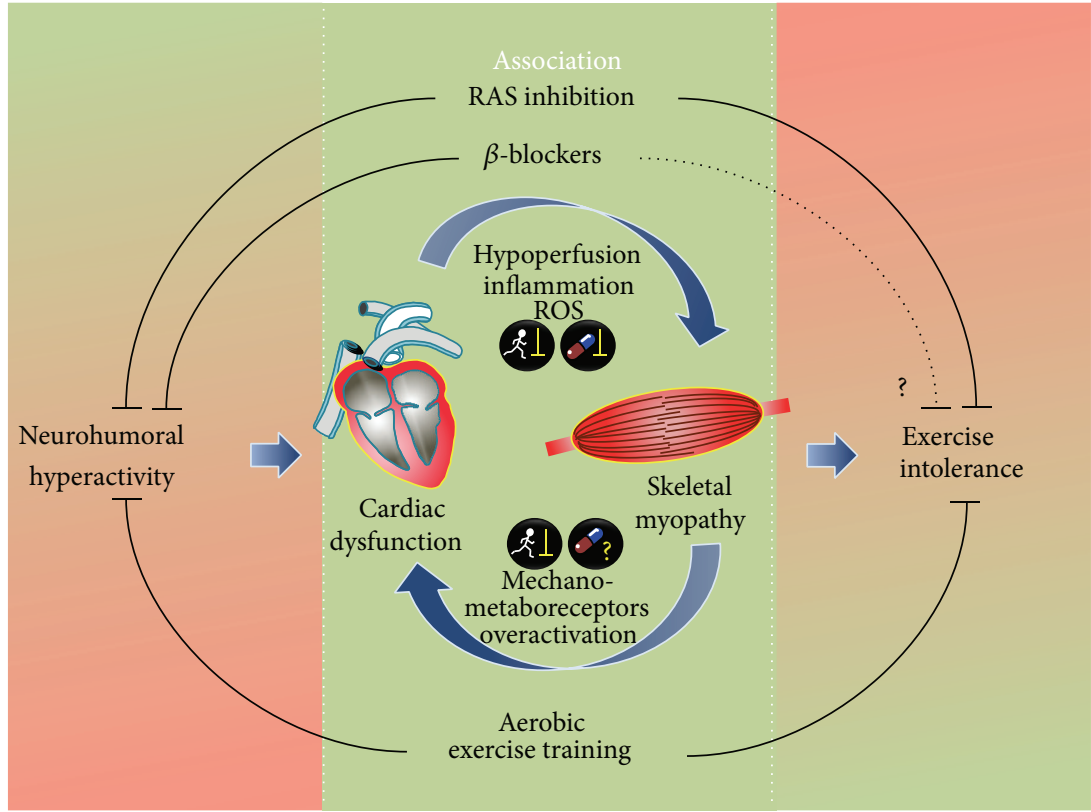

Aerobic exercise training
8 Pharmacological therapies

FiguRE 4: Similarities and differences between aerobic exercise training and neurohumoral blockade in heart failure-induced skeletal myopathy. Skeletal myopathy in heart failure plays a major role in exercise intolerance. Neurohumoral hyperactivity is associated with the pathogenesis of heart failure and also affects skeletal muscle by increasing inflammatory response and oxidative stress and decreasing muscle perfusion. In this perspective, neurohumoral blockade has an important indirect effect on attenuating skeletal myopathy by improving cardiac function and reducing neurohumoral hyperactivity (thick solid lines and $\perp$ ). The efficacy of direct effects of $\beta$-blockade and renin angiotensin aldosterone system inhibition on skeletal muscle still need to be clarified, as exercise intolerance remains in heart failure patients (thin solid lines and $\perp$ ), mainly the ones under $\beta$-blocker therapy (dashed lines and $\perp$ ). In contrast, aerobic exercise training has been considered the most effective strategy to counteract skeletal myopathy and to improve exercise tolerance in heart failure. Therefore, combined neurohumoral inhibition and aerobic exercise training are of great clinical interest in heart failure therapy.

regulation, such as substrate supply availability, oxidative enzyme activities, and mitochondrial content (metabolism) $[125,129] ; \mathrm{Ca}^{2+}$ release and reuptake (contractility) $[137,138]$; and inflammation response and redox balance, reducing skeletal muscle degradation (muscle mass regulation) [20, 21]. Altogether, these AET effects contribute to increasing muscle strength and to improving exercise tolerance and quality of life in HF. Although AET also causes improvements in cardiac function by reducing systemic inflammation and neurohumoral overactivation, there are no studies that provide evidence for a direct link between the reduction of mortality and AET beneficial effects. In contrast, neurohumoral pharmacological blockade reducing HF mortality changed the HF therapy in late 80's [180]. In fact, AET is considered an adjuvant therapy in $\mathrm{HF}$, contributing to minimizing systemic effects and to improving or reverting skeletal myopathy. In the same way, more studies should be conducted to elucidate the role of neurohumoral blockade, $\beta$-blockers, and RAS inhibitors, in counteracting skeletal myopathy, since the effects of neurohumoral blockade on different features of skeletal myopathy are of low magnitude. Therefore, the combined effects of neurohumoral blockade and AET on HF-induced skeletal myopathy are of great clinical interest. In fact, HF mice submitted to combined carvedilol
( $\beta$-blocker) and AET therapies show an integration of distinctly different beneficial effects of isolated therapies on exercise capacity, ventricular function, and remodeling associated with improved $\mathrm{Ca}^{2+}$ homeostasis and reduced ventricular oxidative stress [191]. The summary of the association of neurohumoral blockade and AET on skeletal myopathy is depicted in Figure 4.

In conclusion, an association between pharmacological treatment and AET is currently the most efficient strategy to treat the cardiac dysfunction and skeletal myopathy, improving exercise tolerance and quality of life in HF. It is expected for the future that an association between more selective/specific drugs and AET optimizes the treatment, increasing the responsiveness and outcomes.

\section{Conflict of Interests}

The authors declare that there is no conflict of interests regarding the publication of this paper.

\section{Acknowledgments}

Patricia C. Brum holds grants from Fundação de Amparo à Pesquisa do Estado de São Paulo (FAPESP, no. 2010/50048-1 
and no. 2014/25957-9) and Conselho Nacional de Pesquisa e Desenvolvimento (CNPq, no. 302201/2011-4).

\section{References}

[1] J. Lindenfeld, N. M. Albert, J. P. Boehmer et al., "HFSA 2010 comprehensive heart failure practice guideline," Journal of Cardiac Failure, vol. 16, pp. el-e194, 2010.

[2] J. Farkas, S. von Haehling, K. Kalantar-Zadeh, J. E. Morley, S. D. Anker, and M. Lainscak, "Cachexia as a major public health problem: frequent, costly, and deadly, Journal of Cachexia, Sarcopenia and Muscle, vol. 4, no. 3, pp. 173-178, 2013.

[3] J. E. Morley, D. R. Thomas, and M.-M. G. Wilson, "Cachexia: pathophysiology and clinical relevance," The American Journal of Clinical Nutrition, vol. 83, no. 4, pp. 735-743, 2006.

[4] S. von Haehling and S. D. Anker, "Cachexia as a major underestimated and unmet medical need: facts and numbers," Journal of Cachexia, Sarcopenia and Muscle, vol. 1, no. 1, pp. 1-5, 2010.

[5] S. von Haehling and S. D. Anker, "Cachexia vs obesity: where is the real unmet clinical need?" Journal of Cachexia, Sarcopenia and Muscle, vol. 4, no. 4, pp. 245-246, 2013.

[6] P. C. Brum, A. V. N. Bacurau, A. Medeiros, J. C. B. Ferreira, A. S. Vanzelli, and C. E. Negrão, "Aerobic exercise training in heart failure: impact on sympathetic hyperactivity and cardiac and skeletal muscle function," Brazilian Journal of Medical and Biological Research, vol. 44, no. 9, pp. 827-835, 2011.

[7] C. E. Negrao and H. R. Middlekauff, "Adaptations in autonomic function during exercise training in heart failure," Heart Failure Reviews, vol. 13, no. 1, pp. 51-60, 2008.

[8] D. P. Lipkin, D. A. Jones, J. M. Round, and P. A. Poole-Wilson, "Abnormalities of skeletal muscle in patients with chronic heart failure," International Journal of Cardiology, vol. 18, no. 2, pp. 187-195, 1988.

[9] C. C. Lang, G. H. Rayos, D. B. Chomsky, A. J. J. Wood, and J. R. Wilson, "Effect of sympathoinhibition on exercise performance in patients with heart failure," Circulation, vol. 96, no. 1, pp. 238245, 1997.

[10] H. R. Middlekauff, "Making the case for skeletal myopathy as the major limitation of exercise capacity in heart failure," Circulation: Heart Failure, vol. 3, no. 4, pp. 537-546, 2010.

[11] L. R. G. Bechara, J. B. N. Moreira, P. R. Jannig et al., "NADPH oxidase hyperactivity induces plantaris atrophy in heart failure rats," International Journal of Cardiology, vol. 175, no. 3, pp. 499507, 2014.

[12] P. K. Singal, N. Kapur, K. S. Dhillon, R. E. Beamish, and N. S. Dhalla, "Role of free radicals in catecholamine-induced cardiomyopathy," Canadian Journal of Physiology and Pharmacology, vol. 60, no. 11, pp. 1390-1397, 1982.

[13] P. K. Singal, R. E. Beamish, and N. S. Dhalla, "Potential oxidative pathways of catecholamines in the formation of lipid peroxides and genesis of heart disease," Advances in Experimental Medicine and Biology, vol. 161, pp. 391-401, 1983.

[14] J. K. Shoemaker, H. L. Naylor, C. S. Hogeman, and L. I. Sinoway, "Blood flow dynamics in heart failure," Circulation, vol. 99, no. 23, pp. 3002-3008, 1999.

[15] C. E. Negrão, M. U. P. Brandão Rondon, T. Tinucci et al., "Abnormal neurovascular control during exercise is linked to heart failure severity," American Journal of Physiology: Heart and Circulatory Physiology, vol. 280, no. 3, pp. H1286-H1292, 2001.

[16] M. F. Piepoli, K. Dimopoulos, A. Concu, and A. Crisafulli, "Cardiovascular and ventilatory control during exercise in chronic heart failure: role of muscle reflexes," International Journal of Cardiology, vol. 130, no. 1, pp. 3-10, 2008.

[17] M. F. Piepoli, A. C. Scott, A. Capucci, and A. J. S. Coats, "Skeletal muscle training in chronic heart failure," Acta Physiologica Scandinavica, vol. 171, no. 3, pp. 295-303, 2001.

[18] M. F. Piepoli and A. J. S. Coats, "The 'skeletal muscle hypothesis in heart failure' revised," European Heart Journal, vol. 34, no. 7, pp. 486-488, 2013.

[19] J. S. Floras, "Clinical aspects of sympathetic activation and parasympathetic withdrawal in heart failure," Journal of the American College of Cardiology, vol. 22, supplement 1, no. 4, pp. A72-A84, 1993.

[20] T. F. Cunha, A. V. N. Bacurau, J. B. N. Moreira et al., "Exercise training prevents oxidative stress and ubiquitin-proteasome system overactivity and reverse skeletal muscle atrophy in heart failure," PLoS ONE, vol. 7, no. 8, Article ID e41701, 2012.

[21] S. Gielen, M. Sandri, I. Kozarez et al., "Exercise training attenuates MuRF-1 expression in the skeletal muscle of patients with chronic heart failure independent of age: the randomized leipzig exercise intervention in chronic heart failure and aging catabolism study," Circulation, vol. 125, no. 22, pp. 2716-2727, 2012.

[22] V. M. Conraads, P. Beckers, J. Bosmans et al., "Combined endurance/resistance training reduces plasma TNF-alpha receptor levels in patients with chronic heart failure and coronary artery disease," European Heart Journal, vol. 23, no. 23, pp. 1854-1860, 2002.

[23] S. Gielen, V. Adams, S. Möbius-Winkler et al., "Anti-inflammatory effects of exercise training in the skeletal muscle of patients with chronic heart failure," Journal of the American College of Cardiology, vol. 42, no. 5, pp. 861-868, 2003.

[24] R. Fraga, F. G. Franco, F. Roveda et al., "Exercise training reduces sympathetic nerve activity in heart failure patients treated with carvedilol," European Journal of Heart Failure, vol. 9, no. 6-7, pp. 630-636, 2007.

[25] F. Roveda, H. R. Middlekauff, M. U. P. B. Rondon et al., "The effects of exercise training on sympathetic neural activation in advanced heart failure: a randomized controlled trial," Journal of the American College of Cardiology, vol. 42, no. 5, pp. 854-860, 2003.

[26] A. J. S. Coats, A. L. Clark, M. Piepoli, M. Volterrani, and P. A. Poole-Wilson, "Symptoms and quality of life in heart failure: the muscle hypothesis," British Heart Journal, vol. 72, no. 2, pp. S36S39, 1994.

[27] A. Medeiros, N. P. L. Rolim, R. S. F. Oliveira et al., "Exercise training delays cardiac dysfunction and prevents calcium handling abnormalities in sympathetic hyperactivity-induced heart failure mice," Journal of Applied Physiology, vol. 104, no. 1, pp. 103-109, 2008.

[28] I. L. Gomes-Santos, T. Fernandes, G. K. Couto et al., "Effects of exercise training on circulating and skeletal muscle reninangiotensin system in chronic heart failure rats," PLOS ONE, vol. 9, no. 5, Article ID e98012, 2014.

[29] A. V. N. Bacurau, M. A. Jardim, J. C. B. Ferreira et al., "Sympathetic hyperactivity differentially affects skeletal muscle mass in developing heart failure: role of exercise training," Journal of Applied Physiology, vol. 106, no. 5, pp. 1631-1640, 2009.

[30] S. J. Peters, D. J. Dyck, A. Bonen, and L. L. Spriet, "Effects of epinephrine on lipid metabolism in resting skeletal muscle," The American Journal of Physiology-Endocrinology and Metabolism, vol. 275, no. 2, pp. E300-E309, 1998. 
[31] J. H. Williams and W. S. Barnes, "The positive inotropic effect of epinephrine on skeletal muscle: a brief review," Muscle and Nerve, vol. 12, no. 12, pp. 968-975, 1989.

[32] M. S. Elfellah, R. Dalling, I. M. Kantola, and J. L. Reid, “ $\beta$ adrenoceptors and human skeletal muscle characterisation of receptor subtype and effect of age," British Journal of Clinical Pharmacology, vol. 27, no. 1, pp. 31-38, 1989.

[33] S. B. Liggett, S. D. Shah, and P. E. Cryer, "Increased fat and skeletal muscle beta-adrenergic receptors but unaltered metabolic and hemodynamic sensitivity to epinephrine in vivo in experimental human thyrotoxicosis," The Journal of Clinical Investigation, vol. 83, no. 3, pp. 803-809, 1989.

[34] O. A. Coman, H. Păunescu, I. Ghiţă, L. Coman, A. Bădărăru, and I. Fulga, "Beta 3 adrenergic receptors: molecular, histological, functional and pharmacological approaches," Romanian Journal of Morphology and Embryology, vol. 50, no. 2, pp. 169179, 2009.

[35] J. Jensen, O. Brors, and H. A. Dahl, "Different $\beta$-adrenergic receptor density in different rat skeletal muscle fibre types," Pharmacology and Toxicology, vol. 76, no. 6, pp. 380-385, 1995.

[36] Y. S. Kim, R. D. Sainz, P. Molenaar, and R. J. Summers, "Characterization of $\beta 1$ - and $\beta 2$-adrenoceptors in rat skeletal muscles," Biochemical Pharmacology, vol. 42, no. 9, pp. 1783-1789, 1991

[37] W. H. Martin III, S. Murphree, and J. E. Saffitz, "beta-adrenergic receptor distribution among muscle fiber types and resistance arterioles of white, red, and intermediate skeletal muscle," Circulation Research, vol. 64, no. 6, pp. 1096-1105, 1989.

[38] J. G. Ryall, P. Gregorevic, D. R. Plant, M. N. Sillence, and G. S. Lynch, " $\beta 2$-agonist fenoterol has greater effects on contractile function of rat skeletal muscles than clenbuterol," American Journal of Physiology-Regulatory Integrative and Comparative Physiology, vol. 283, no. 6, pp. R1386-R1394, 2002.

[39] J. G. Ryall, D. R. Plant, P. Gregorevic, M. N. Sillence, and G. S. Lynch, " $\beta 2$-agonist administration reverses muscle wasting and improves muscle function in aged rats," Journal of Physiology, vol. 555, no. 1, pp. 175-188, 2004.

[40] Y. S. Kim, R. D. Sainz, R. J. Summers, and P. Molenaar, "Cimaterol reduces beta-adrenergic receptor density in rat skeletal muscles," Journal of Animal Science, vol. 70, no. 1, pp. 115-122, 1992.

[41] J. Jensen, E. O. Brennesvik, L. H. Bergersen, H. Oseland, E. Jebens, and O. Brørs, "Quantitative determination of cell surface $\beta$-adrenoceptors in different rat skeletal muscles," Pflugers Archiv, vol. 444, no. 1-2, pp. 213-219, 2002.

[42] J. G. Ryall, M. N. Sillence, and G. S. Lynch, "Systemic administration of beta2-adrenoceptor agonists, formoterol and salmeterol, elicit skeletal muscle hypertrophy in rats at micromolar doses," British Journal of Pharmacology, vol. 147, no. 6, pp. 587595, 2006.

[43] E. Hagström-Toft, S. Enoksson, E. Moberg, J. Bolinder, and P. Arner, " $\beta$-adrenergic regulation of lipolysis and blood flow in human skeletal muscle in vivo," American Journal of Physiology: Endocrinology and Metabolism, vol. 275, no. 6, pp. E909-E916, 1998.

[44] J. Hoeks, M. A. van Baak, M. K. C. Hesselink et al., "Effect of betal- and beta2-adrenergic stimulation on energy expenditure, substrate oxidation, and UCP3 expression in humans," The American Journal of Physiology-Endocrinology and Metabolism, vol. 285, no. 4, pp. E775-E782, 2003.

[45] M. R. Dietz, J. L. Chiasson, T. R. Soderling, and J. H. Exton, "Epinephrine regulation of skeletal muscle glycogen metabolism. Studies utilizing the perfused rat hindlimb preparation," Journal of Biological Chemistry, vol. 255, no. 6, pp. 23012307, 1980.

[46] I. Raz, A. Katz, and M. K. Spencer, "Epinephrine inhibits insulin-mediated glycogenesis but enhances glycolysis in human skeletal muscle," The American Journal of PhysiologyEndocrinology and Metabolism, vol. 260, no. 3, pp. E430-E435, 1991.

[47] A. I. Öberg, $\beta$-adrenergic signalling and novel effects in skeletal muscle [Ph.D. thesis], Stockholm University, Stockholm, Sweden, 2013.

[48] G. W. Fernandes, C. B. Ueta, T. L. Fonseca et al., "Inactivation of the adrenergic receptor $\beta_{2}$ disrupts glucose homeostasis in mice," Journal of Endocrinology, vol. 221, no. 3, pp. 381-390, 2014.

[49] A. Schmid, J.-F. Renaud, and M. Lazdunski, "Short term and long term effects of $\beta$-adrenergic effectors and cyclic AMP on nitrendipine-sensitive voltage-dependent $\mathrm{Ca}^{2+}$ channels of skeletal muscle," The Journal of Biological Chemistry, vol. 260, no. 24, pp. 13041-13046, 1985.

[50] J. Suko, I. Maurer-Fogy, B. Plank et al., "Phosphorylation of serine 2843 in ryanodine receptor-calcium release channel of skeletal muscle by cAMP-, cGMP- and CaM-dependent protein kinase," Biochimica et Biophysica Acta-Molecular Cell Research, vol. 1175, no. 2, pp. 193-206, 1993.

[51] M. Tadaishi, S. Miura, Y. Kai et al., "Effect of exercise intensity and AICAR on isoform-specific expressions of murine skeletal muscle PGC- $1 \alpha$ mRNA: a role of $\beta 2$-adrenergic receptor activation," American Journal of Physiology: Endocrinology and Metabolism, vol. 300, no. 2, pp. E341-E349, 2011.

[52] S. Miura, Y. Kai, Y. Kamei, and O. Ezaki, "Isoform-specific increases in murine skeletal muscle peroxisome proliferatoractivated receptor- $\gamma$ coactivator- $1 \alpha$ (PGC-1 $\alpha$ ) mRNA in response to $\beta 2$-adrenergic receptor activation and exercise," Endocrinology, vol. 149, no. 9, pp. 4527-4533, 2008.

[53] S. Miura, K. Kawanaka, Y. Kai et al., "An increase in murine skeletal muscle peroxisome proliferator-activated receptor- $\gamma$ coactivator- $1 \alpha$ (PGC- $1 \alpha$ ) mRNA in response to exercise is mediated by $\beta$-adrenergic receptor activation," Endocrinology, vol. 148, no. 7, pp. 3441-3448, 2007.

[54] M. M. Robinson, C. Bell, F. F. Peelor III, and B. F. Miller, “ $\beta$ adrenergic receptor blockade blunts postexercise skeletal muscle mitochondrial protein synthesis rates in humans," American Journal of Physiology-Regulatory Integrative and Comparative Physiology, vol. 301, no. 2, pp. R327-R334, 2011.

[55] L. P. Wills, R. E. Trager, G. C. Beeson et al., "The $\beta 2$-adrenoceptor agonist formoterol stimulates mitochondrial biogenesis," Journal of Pharmacology and Experimental Therapeutics, vol. 342, no. 1, pp. 106-118, 2012.

[56] F. Valsecchi, L. S. Ramos-Espiritu, J. Buck, L. R. Levin, and G. Manfredi, "cAMP and mitochondria," Physiology, vol. 28, no. 3, pp. 199-209, 2013.

[57] F. X. Soriano, M. Liesa, D. Bach, D. C. Chan, M. Palacín, and A. Zorzano, "Evidence for a mitochondrial regulatory pathway defined by peroxisome proliferator-activated receptor$\gamma$ coactivator- $1 \alpha$, estrogen-related receptor- $\alpha$, and mitofusin 2 ," Diabetes, vol. 55, no. 6, pp. 1783-1791, 2006.

[58] O. R. Joassard, A. Amirouche, Y. S. Gallot et al., "Regulation of Akt-mTOR, ubiquitin-proteasome and autophagy-lysosome pathways in response to formoterol administration in rat skeletal muscle," The International Journal of Biochemistry \& Cell Biology, vol. 45, no. 11, pp. 2444-2455, 2013. 
[59] D. De Rasmo, G. Gattoni, F. Papa et al., “The $\beta$-adrenoceptor agonist isoproterenol promotes the activity of respiratory chain complex I and lowers cellular reactive oxygen species in fibroblasts and heart myoblasts," European Journal of Pharmacology, vol. 652, no. 1-3, pp. 15-22, 2011.

[60] R. K. Dagda, A. M. Gusdon, I. Pien et al., "Mitochondrially localized PKA reverses mitochondrial pathology and dysfunction in a cellular model of Parkinson's disease," Cell Death \& Differentiation, vol. 18, no. 12, pp. 1914-1923, 2011.

[61] S. Busquets, M. T. Figueras, G. Fuster et al., "Anticachectic effects of formoterol: a drug for potential treatment of muscle wasting," Cancer Research, vol. 64, no. 18, pp. 6725-6731, 2004.

[62] M. T. Silva, L. A. Wensing, P. C. Brum, N. O. Camara, and E. H. Miyabara, "Impaired structural and functional regeneration of skeletal muscles from $\beta 2$-adrenoceptor knockout mice," Acta Physiologica, vol. 211, no. 4, pp. 617-633, 2014.

[63] S. W. Jones, D. J. Baker, and P. L. Greenhaff, "G protein-coupled receptor kinases 2 and 5 are differentially expressed in rat skeletal muscle and remain unchanged following $\beta 2$-agonist administration," Experimental Physiology, vol. 88, no. 2, pp. 277284, 2003.

[64] G. S. Lynch and J. G. Ryall, "Role of beta-adrenoceptor signaling in skeletal muscle: implications for muscle wasting and disease," Physiological Reviews, vol. 88, no. 2, pp. 729-767, 2008.

[65] L. C. C. Navegantes, R. H. Migliorini, and I. do Carmo Kettelhut, "Adrenergic control of protein metabolism in skeletal muscle," Current Opinion in Clinical Nutrition and Metabolic Care, vol. 5, no. 3, pp. 281-286, 2002.

[66] Y. T. Yang and M. A. McElligott, "Multiple actions of $\beta$-adrenergic agonists on skeletal muscle and adipose tissue," Biochemical Journal, vol. 261, no. 1, pp. 1-10, 1989.

[67] S. Agrawal, P. Thakur, and S. S. Katoch, "Beta adrenoceptor agonists, clenbuterol, and isoproterenol retard denervation atrophy in rat gastrocnemius muscle: use of 3-methylhistidine as a marker of myofibrillar degeneration," Japanese Journal of Physiology, vol. 53, no. 3, pp. 229-237, 2003.

[68] L. C. C. Navegantes, N. M. Z. Resano, R. H. Migliorini, and Í. C. Kettelhut, "Role of adrenoceptors and cAMP on the catecholamine-induced inhibition of proteolysis in rat skeletal muscle," The American Journal of Physiology-Endocrinology and Metabolism, vol. 279, no. 3, pp. E663-E668, 2000.

[69] L. C. C. Navegantes, N. M. Z. Resano, R. H. Migliorini, and I. C. Kettelhut, "Effect of guanethidine-induced adrenergic blockade on the different proteolytic systems in rat skeletal muscle," American Journal of Physiology: Endocrinology and Metabolism, vol. 277, no. 5, pp. E883-E889, 1999.

[70] P. Molenaar, L. Chen, and W. A. Parsonage, "Cardiac implications for the use of $\beta 2$-adrenoceptor agonists for the management of muscle wasting," British Journal of Pharmacology, vol. 147, no. 6, pp. 583-586, 2006.

[71] I. George, S. Xydas, D. M. Mancini et al., "Effect of clenbuterol on cardiac and skeletal muscle function during left ventricular assist device support," Journal of Heart and Lung Transplantation, vol. 25, no. 9, pp. 1084-1090, 2006.

[72] V. A. Voltarelli, L. R. G. Bechara, A. V. N. Bacurau et al., "Lack of $\beta 2$-adrenoceptors aggravates heart failure-induced skeletal muscle myopathy in mice," Journal of Cellular and Molecular Medicine, vol. 18, no. 6, pp. 1087-1097, 2014.

[73] N. J. Rothwell, M. J. Stock, and D. K. Sudera, "Changes in tissue blood flow and beta-receptor density of skeletal muscle in rats treated with the beta2-adrenoceptor agonist clenbuterol," British Journal of Pharmacology, vol. 90, no. 3, pp. 601-607, 1987.
[74] The Consensus Trial Study Group, "Effects of enalapril on mortality in severe congestive heart failure. Results of the Cooperative North Scandinavian Enalapril Survival Study (CONSENSUS)," The New England Journal of Medicine, vol. 316, no. 23, pp. 1429-1435, 1987.

[75] The SOLVD Investigators, "Effect of enalapril on survival in patients with reduced left ventricular ejection fractions and congestive heart failure," The New England Journal of Medicine, vol. 325, no. 5, pp. 293-302, 1991.

[76] R. Garg and S. Yusuf, "Overview of randomized trials of angiotensin-converting enzyme inhibitors on mortality and morbidity in patients with heart failure," The Journal of the American Medical Association, vol. 273, no. 18, pp. 1450-1456, 1995.

[77] C. M. Ferrario and W. B. Strawn, "Role of the renin-angiotensinaldosterone system and proinflammatory mediators in cardiovascular disease," American Journal of Cardiology, vol. 98, no. 1, pp. 121-128, 2006.

[78] R. J. Mentz, G. L. Bakris, B. Waeber et al., "The past, present and future of renin-angiotensin aldosterone system inhibition," International Journal of Cardiology, vol. 167, no. 5, pp. 1677-1687, 2013.

[79] S. D. Anker, A. Negassa, A. J. S. Coats et al., "Prognostic importance of weight loss in chronic heart failure and the effect of treatment with angiotensin-converting-enzyme inhibitors: an observational study," The Lancet, vol. 361, no. 9363, pp. 10771083, 2003.

[80] T. Yoshida and P. Delafontaine, "Mechanisms of cachexia in chronic disease states," The American Journal of the Medical Sciences, 2015.

[81] W. J. Evans, J. E. Morley, J. Argilés et al., "Cachexia: a new definition," Clinical Nutrition, vol. 27, no. 6, pp. 793-799, 2008.

[82] P. E. Ward, J. S. Russell, and P. L. Vaghy, "Angiotensin and bradykinin metabolism by peptidases identified in skeletal muscle," Peptides, vol. 16, no. 6, pp. 1073-1078, 1995.

[83] A. P. W. Johnston, J. Baker, M. De Lisio, and G. Parise, "Skeletal muscle myoblasts possess a stretch-responsive local angiotensin signalling system," Journal of Renin-Angiotensin-Aldosterone System, vol. 12, no. 2, pp. 75-84, 2011.

[84] M. Brink, J. Wellen, and P. Delafontaine, "Angiotensin II causes weight loss and decreases circulating insulin-like growth factor I in rats through a pressor-independent mechanism," The Journal of Clinical Investigation, vol. 97, no. 11, pp. 2509-2516, 1996.

[85] M. Brink, S. R. Price, J. Chrast et al., "Angiotensin II induces skeletal muscle wasting through enhanced protein degradation and down-regulates autocrine insulin-like growth factor I," Endocrinology, vol. 142, no. 4, pp. 1489-1496, 2001.

[86] F. Folli, C. R. Kahn, H. Hansen, J. L. Bouchie, and E. P. Feener, "Angiotensin II inhibits insulin signaling in aortic smooth muscle cells at multiple levels. A potential role for serine phosphorylation in insulin/angiotensin II crosstalk," The Journal of Clinical Investigation, vol. 100, no. 9, pp. 2158-2169, 1997.

[87] L. A. Velloso, F. Folli, L. Perego, and M. J. A. Saad, "The multi-faceted cross-talk between the insulin and angiotensin II signaling systems," Diabetes/Metabolism Research and Reviews, vol. 22, no. 2, pp. 98-107, 2006.

[88] Y.-H. Song, Y. Li, J. Du, W. E. Mitch, N. Rosenthal, and P. Delafontaine, "Muscle-specific expression of IGF-1 blocks angiotensin II-induced skeletal muscle wasting," The Journal of Clinical Investigation, vol. 115, no. 2, pp. 451-458, 2005. 
[89] C. Werner, J. Pöss, and M. Böhm, “Optimal antagonism of the renin-angiotensin-aldosterone system: do we need dual or triple therapy?” Drugs, vol. 70, no. 10, pp. 1215-1230, 2010.

[90] T. Yoshida, L. Semprun-Prieto, S. Sukhanov, and P. Delafontaine, "IGF-1 prevents ANG II-induced skeletal muscle atrophy via Akt- and Foxo-dependent inhibition of the ubiquitin ligase atrogin-1 expression," American Journal of Physiology: Heart and Circulatory Physiology, vol. 298, no. 5, pp. H1565H1570, 2010.

[91] L. C. Semprun-Prieto, S. Sukhanov, T. Yoshida et al., "Angiotensin II induced catabolic effect and muscle atrophy are redox dependent," Biochemical and Biophysical Research Communications, vol. 409, no. 2, pp. 217-221, 2011.

[92] T. Yoshida, S. Galvez, S. Tiwari et al., "Angiotensin II inhibits satellite cell proliferation and prevents skeletal muscle regeneration," The Journal of Biological Chemistry, vol. 288, no. 33, pp. 23823-23832, 2013.

[93] T. Yoshida, A. M. Tabony, S. Galvez et al., "Molecular mechanisms and signaling pathways of angiotensin II-induced muscle wasting: potential therapeutic targets for cardiac cachexia," The International Journal of Biochemistry \& Cell Biology, vol. 45, no. 10, pp. 2322-2332, 2013.

[94] A. M. Tabony, T. Yoshida, S. Galvez et al., "Angiotensin II upregulates protein phosphatase $2 \mathrm{C} \alpha$ and inhibits AMP-activated protein kinase signaling and energy balance leading to skeletal muscle wasting," Hypertension, vol. 58, no. 4, pp. 643-649, 2011.

[95] F. L. Muller, W. Song, Y. C. Jang et al., "Denervation-induced skeletal muscle atrophy is associated with increased mitochondrial ROS production," American Journal of Physiology: Regulatory Integrative and Comparative Physiology, vol. 293, no. 3, pp. R1159-R1168, 2007.

[96] N. P. Whitehead, E. W. Yeung, S. C. Froehner, and D. G. Allen, "Skeletal muscle NADPH oxidase is increased and triggers stretch-induced damage in the mdx mouse," PLoS ONE, vol. 5, no. 12, Article ID e15354, 2010.

[97] L. Zhang, J. Du, Z. Hu et al., "IL-6 and serum amyloid A synergy mediates angiotensin ll-Lnduced muscle wasting," Journal of the American Society of Nephrology, vol. 20, no. 3, pp. 604-612, 2009.

[98] L. Dalla Libera, B. Ravara, A. Angelini et al., "Beneficial effects on skeletal muscle of the angiotensin II type 1 receptor blocker irbesartan in experimental heart failure," Circulation, vol. 103, no. 17, pp. 2195-2200, 2001.

[99] G. Onder, B. W. J. H. Penninx, R. Balkrishnan et al., "Relation between use of angiotensin-converting enzyme inhibitors and muscle strength and physical function in older women: an observational study," The Lancet, vol. 359, no. 9310, pp. 926-930, 2002.

[100] D. Sumukadas, M. D. Witham, A. D. Struthers, and M. E. T. McMurdo, "Effect of perindopril on physical function in elderly people with functional impairment: a randomized controlled trial," Canadian Medical Association Journal, vol. 177, no. 8, pp. 867-874, 2007.

[101] C. Coirault, A. Hagège, D. Chemla, M.-D. Fratacci, C. Guérot, and Y. Lecarpentier, "Angiotensin-converting enzyme inhibitor therapy improves respiratory muscle strength in patients with heart failure," Chest, vol. 119, no. 6, pp. 1755-1760, 2001.

[102] J. Zoll, L. Monassier, A. Garnier et al., "ACE inhibition prevents myocardial infarction-induced skeletal muscle mitochondrial dysfunction," Journal of Applied Physiology, vol. 101, no. 2, pp. 385-391, 2006.

[103] X. Feng, Z. Luo, L. Ma et al., "Angiotensin II receptor blocker telmisartan enhances running endurance of skeletal muscle through activation of the PPAR- $\delta$ /AMPK pathway," Journal of Cellular and Molecular Medicine, vol. 15, no. 7, pp. 1572-1581, 2011.

[104] G. Lastra, F. R. Santos, P. Hooshmand et al., "The novel angiotensin II receptor blocker azilsartan medoxomil ameliorates insulin resistance induced by chronic angiotensin II treatment in rat skeletal muscle," Cardiorenal Medicine, vol. 3, no. 2, pp. 154-164, 2013.

[105] J. G. Burniston, A. Saini, L.-B. Tan, and D. F. Goldspink, "Aldosterone induces myocyte apoptosis in the heart and skeletal muscles of rats in vivo," Journal of Molecular and Cellular Cardiology, vol. 39, no. 2, pp. 395-399, 2005.

[106] Y. Cheema, W. Zhao, T. Zhao et al., "Reverse remodeling and recovery from cachexia in rats with aldosteronism," The American Journal of Physiology-Heart and Circulatory Physiology, vol. 303, no. 4, pp. H486-H495, 2012.

[107] L. A. Burton, M. E. T. McMurdo, and A. D. Struthers, "Mineralocorticoid antagonism: a novel way to treat sarcopenia and physical impairment in older people?" Clinical Endocrinology, vol. 75, no. 6, pp. 725-729, 2011.

[108] T. Yoshida, T. S. Huq, and P. Delafontaine, "Angiotensin type 2 receptor signaling in satellite cells potentiates skeletal muscle regeneration," The Journal of Biological Chemistry, vol. 289, no. 38, pp. 26239-26248, 2014.

[109] R. A. S. Santos, A. C. Simoes e Silva, C. Maric et al., "Angiotensin-(1-7) is an endogenous ligand for the $G$ protein-coupled receptor Mas," Proceedings of the National Academy of Sciences of the United States of America, vol. 100, no. 14, pp. 8258-8263, 2003.

[110] C. Vickers, P. Hales, V. Kaushik et al., "Hydrolysis of biological peptides by human angiotensin-converting enzyme-related carboxypeptidase," Journal of Biological Chemistry, vol. 277, no. 17, pp. 14838-14843, 2002.

[111] T. Fernandes, N. Y. Hashimoto, and E. M. Oliveira, "Characterization of angiotensin-converting enzymes 1 and 2 in the soleus and plantaris muscles of rats," Brazilian Journal of Medical and Biological Research, vol. 43, no. 9, pp. 837-842, 2010.

[112] M. Prasannarong, F. R. Santos, and E. J. Henriksen, "ANG-(17) reduces ANG II-induced insulin resistance by enhancing Akt phosphorylation via a Mas receptor-dependent mechanism in rat skeletal muscle," Biochemical and Biophysical Research Communications, vol. 426, no. 3, pp. 369-373, 2012.

[113] J. Fang, J. Wylie-Rosett, H. W. Cohen, R. C. Kaplan, and M. H. Alderman, "Exercise, body mass index, caloric intake, and cardiovascular mortality," American Journal of Preventive Medicine, vol. 25, no. 4, pp. 283-289, 2003.

[114] R. J. Sigal, G. P. Kenny, D. H. Wasserman, and C. CastanedaSceppa, "Physical activity/exercise and type 2 diabetes," Diabetes Care, vol. 27, no. 10, pp. 2518-2539, 2004.

[115] S. K. Powers, "Exercise, antioxidants, and cardioprotection," Sports Science Exchange, vol. 15, no. 2, p. 85, 2002.

[116] C. A. Emter, S. A. McCune, G. C. Sparagna, M. J. Radin, and R. L. Moore, "Low-intensity exercise training delays onset of decompensated heart failure in spontaneously hypertensive heart failure rats," American Journal of Physiology-Heart and Circulatory Physiology, vol. 289, no. 5, pp. H2030-H2038, 2005.

[117] S. Jónsdóttir, K. K. Andersen, A. F. Sigurosson, and S. B. Sigurosson, "The effect of physical training in chronic heart failure," European Journal of Heart Failure, vol. 8, no. 1, pp. 97101, 2006.

[118] K. Dickstein, A. Cohen-Solal, G. Filippatos et al., "ESC guidelines for the diagnosis and treatment of acute and chronic heart 
failure 2008: the Task Force for the diagnosis and treatment of acute and chronic heart failure 2008 of the European Society of Cardiology. Developed in collaboration with the Heart Failure Association of the ESC (HFA) and endorsed by the European Society of Intensive Care Medicine (ESICM)," European Journal of Heart Failure, vol. 10, no. 10, pp. 933-989, 2008.

[119] S. A. Hunt, W. T. Abraham, M. H. Chin et al., "2009 Focused update incorporated into the ACC/AHA 2005 guidelines for the diagnosis and management of heart failure in adults: a report of the American College of Cardiology Foundation/American Heart Association Task Force on practice guidelines: developed in collaboration with the International Society for Heart and Lung Transplantation," Circulation, vol. 119, no. 14, pp. e391e479, 2009.

[120] V. Adams and J. Niebauer, "Reversing heart failure-associated pathophysiology with exercise: what actually improves and by how much?" Heart Failure Clinics, vol. 11, no. 1, pp. 17-28, 2015.

[121] E. De Sousa, V. Veksler, X. Bigard, P. M. Bing, and R. VenturaClapier, "Heart failure affects mitochondrial but not myofibrillar intrinsic properties of skeletal muscle," Circulation, vol. 102, no. 15, pp. 1847-1853, 2000.

[122] A. Garnier, D. Fortin, C. Deloménie, I. Momken, V. Veksler, and R. Ventura-Clapier, "Depressed mitochondrial transcription factors and oxidative capacity in rat failing cardiac and skeletal muscles," The Journal of Physiology, vol. 551, no. 2, pp. 491-501, 2003.

[123] P. K. Lunde, I. Sjaastad, H.-M. Schiøtz Thorud, and O. M. Sejersted, "Skeletal muscle disorders in heart failure," Acta Physiologica Scandinavica, vol. 171, no. 3, pp. 277-294, 2001.

[124] B. Massie, M. Conway, R. Yonge et al., "Skeletal muscle metabolism in patients with congestive heart failure: relation to clinical severity and blood flow," Circulation, vol. 76, no. 5, pp. 10091019, 1987.

[125] M. F. Piepoli, "Exercise training in chronic heart failure: mechanisms and therapies," Netherlands Heart Journal, vol. 21, no. 2, pp. 85-90, 2013.

[126] R. W. A. Souza, W. P. Piedade, L. C. Soares et al., "Aerobic exercise training prevents heart failure-induced skeletal muscle atrophy by anti-catabolic, but not anabolic actions," PLoS ONE, vol. 9, no. 10, Article ID el10020, 2014.

[127] G. Vescovo, B. Ravara, V. Gobbo, A. Angelini, and L. Dalla Libera, "Skeletal muscle fibres synthesis in heart failure: role of PGC-1alpha, calcineurin and GH," International Journal of Cardiology, vol. 104, no. 3, pp. 298-306, 2005.

[128] G. Vescovo, M. Volterrani, R. Zennaro et al., "Apoptosis in the skeletal muscle of patients with heart failure: investigation of clinical and biochemical changes," Heart, vol. 84, no. 4, pp. 431437, 2000.

[129] M. Ohtsubo, K. Yonezawa, H. Nishijima et al., "Metabolic abnormality of calf skeletal muscle is improved by localised muscle training without changes in blood flow in chronic heart failure," Heart, vol. 78, no. 5, pp. 437-443, 1997.

[130] J. R. Stratton, W. C. Levy, M. D. Cerqueira, R. S. Schwartz, and I. B. Abrass, "Cardiovascular responses to exercise. Effects of aging and exercise training in healthy men," Circulation, vol. 89, no. 4, pp. 1648-1655, 1994.

[131] F. Brunotte, C. H. Thompson, S. Adamopoulos et al., "Rat skeletal muscle metabolism in experimental heart failure: effects of physical training," Acta Physiologica Scandinavica, vol. 154, no. 4, pp. 439-447, 1995.

[132] R. Hambrecht, V. Adams, S. Gielen et al., "Exercise intolerance in patients with chronic heart failure and increased expression of inducible nitric oxide synthase in the skeletal muscle," Journal of the American College of Cardiology, vol. 33, no. 1, pp. 174-179, 1999.

[133] R. Hambrecht, J. Niebauer, E. Fiehn et al., "Physical training in patients with stable chronic heart failure: effects on cardiorespiratory fitness and ultrastructural abnormalities of leg muscles," Journal of the American College of Cardiology, vol. 25, no. 6, pp. 1239-1249, 1995.

[134] R. Hambrecht, E. Fiehn, J. Yu et al., "Effects of endurance training on mitochondrial ultrastructure and fiber type distribution in skeletal muscle of patients with stable chronic heart failure," Journal of the American College of Cardiology, vol. 29, no. 5, pp. 1067-1073, 1997.

[135] C. L. Perreault, H. Gonzalez-Serratos, S. E. Litwin, X. Sun, C. Franzini-Armstrong, and J. P. Morgan, "Alterations in contractility and intracellular Ca2+ transients in isolated bundles of skeletal muscle fibers from rats with chronic heart failure," Circulation Research, vol. 73, no. 2, pp. 405-412, 1993.

[136] H. R. Middlekauff, C. Vigna, M. A. Verity et al., "Abnormalities of calcium handling proteins in skeletal muscle mirror those of the heart in humans with heart failure: a shared mechanism?" Journal of Cardiac Failure, vol. 18, no. 9, pp. 724-733, 2012.

[137] C. R. Bueno Jr., J. C. B. Ferreira, M. G. Pereira, A. V. N. Bacurau, and P. C. Brum, "Aerobic exercise training improves skeletal muscle function and $\mathrm{Ca}^{2+}$ handling-related protein expression in sympathetic hyperactivity-induced heart failure," Journal of Applied Physiology, vol. 109, no. 3, pp. 702-709, 2010.

[138] M. Munkvik, T. A. Rehn, G. Slettaløkken et al., “Training effects on skeletal muscle calcium handling in human chronic heart failure," Medicine and Science in Sports and Exercise, vol. 42, no. 5, pp. 847-855, 2010.

[139] S. D. Anker, P. Ponikowski, S. Varney et al., "Wasting as independent risk factor for mortality in chronic heart failure," The Lancet, vol. 349, no. 9058, pp. 1050-1053, 1997.

[140] L. Dalla Libera, R. Sabbadini, C. Renken et al., "Apoptosis in the skeletal muscle of rats with heart failure is associated with increased serum levels of TNF-alpha and sphingosine," Journal of Molecular and Cellular Cardiology, vol. 33, no. 10, pp. 18711878, 2001.

[141] A. Linke, V. Adams, P. C. Schulze et al., "Antioxidative effects of exercise training in patients with chronic heart failure: increase in radical scavenger enzyme activity in skeletal muscle," Circulation, vol. 111, no. 14, pp. 1763-1770, 2005.

[142] M. Cicoira, A. P. Bolger, W. Doehner et al., "High tumour necrosis factor- $\alpha$ levels are associated with exercise intolerance and neurohormonal activation in chronic heart failure patients," Cytokine, vol. 15, no. 2, pp. 80-86, 2001.

[143] G. J. J. Silva, P. C. Brum, C. E. Negrão, and E. M. Krieger, "Acute and chronic effects of exercise on baroreflexes in spontaneously hypertensive rats," Hypertension, vol. 30, no. 3, pp. 714-719, 1997.

[144] P. C. Brum, G. J. J. Da Silva, E. D. Moreira, F. Ida, C. E. Negrão, and E. M. Krieger, "Exercise training increases baroreceptor gain sensitivity in normal and hypertensive rats," Hypertension, vol. 36, no. 6, pp. 1018-1022, 2000.

[145] J.-L. Liu, S. Irvine, I. A. Reid, K. P. Patel, and I. H. Zucker, "Chronic exercise reduces sympathetic nerve activity in rabbits with pacing-induced heart failure: a role for angiotensin II," Circulation, vol. 102, no. 15, pp. 1854-1862, 2000.

[146] H.-J. Wang, Y.-L. Li, I. H. Zucker, and W. Wang, "Exercise training prevents skeletal muscle afferent sensitization in rats with chronic heart failure," American Journal of Physiology: 
Regulatory Integrative and Comparative Physiology, vol. 302, no. 11, pp. R1260-R1270, 2012.

[147] L. C. Michelini and J. E. Stern, "Exercise-induced neuronal plasticity in central autonomic networks: role in cardiovascular control," Experimental Physiology, vol. 94, no. 9, pp. 947-960, 2009.

[148] S. Kar, L. Gao, and I. H. Zucker, "Exercise training normalizes ACE and ACE2 in the brain of rabbits with pacing-induced heart failure," Journal of Applied Physiology, vol. 108, no. 4, pp. 923-932, 2010.

[149] L. M. Antunes-Correa, T. S. Nobre, R. V. Groehs et al., "Molecular basis for the improvement in muscle metaboreflex and mechanoreflex control in exercise-trained humans with chronic heart failure," American Journal of Physiology-Heart and Circulatory Physiology, vol. 307, no. 11, pp. H1655-H1666, 2014.

[150] I. H. Zucker, L. Xiao, and K. K. V. Haack, "The central reninangiotensin system and sympathetic nerve activity in chronic heart failure," Clinical Science, vol. 126, no. 10, pp. 695-706, 2014.

[151] W. Zhao, S. A. Swanson, J. Ye et al., "Reactive oxygen species impair sympathetic vasoregulation in skeletal muscle in angiotensin II-dependent hypertension," Hypertension, vol. 48, no. 4, pp. 637-643, 2006.

[152] J. Niebauer, "Inflammatory mediators in heart failure," International Journal of Cardiology, vol. 72, no. 3, pp. 209-213, 2000.

[153] S. Acharyya, K. J. Ladner, L. L. Nelsen et al., "Cancer cachexia is regulated by selective targeting of skeletal muscle gene products," The Journal of Clinical Investigation, vol. 114, no. 3, pp. 370-378, 2004.

[154] S. Adamopoulos, J. Parissis, C. Kroupis et al., "Physical training reduces peripheral markers of inflammation in patients with chronic heart failure," European Heart Journal, vol. 22, no. 9, pp. 791-797, 2001.

[155] N. Mangner, A. Linke, A. Oberbach et al., "Exercise training prevents TNF-alpha induced loss of force in the diaphragm of mice," PLoS ONE, vol. 8, no. 1, Article ID e52274, 2013.

[156] J. S. Moylan and M. B. Reid, "Oxidative stress, chronic disease, and muscle wasting," Muscle and Nerve, vol. 35, no. 4, pp. 411429, 2007.

[157] M. C. C. Gomes-Marcondes and M. J. Tisdale, "Induction of protein catabolism and the ubiquitin-proteasome pathway by mild oxidative stress," Cancer Letters, vol. 180, no. 1, pp. 69-74, 2002.

[158] Y.-P. Li, Y. Chen, A. S. Li, and M. B. Reid, "Hydrogen peroxide stimulates ubiquitin-conjugating activity and expression of genes for specific E2 and E3 proteins in skeletal muscle myotubes," The American Journal of Physiology-Cell Physiology, vol. 285, no. 4, pp. C806-C812, 2003.

[159] J. B. N. Moreira, L. R. G. Bechara, L. H. M. Bozi et al., "Highversus moderate-intensity aerobic exercise training effects on skeletal muscle of infarcted rats," Journal of Applied Physiology, vol. 114, no. 8, pp. 1029-1041, 2013.

[160] D. Attaix, L. Combaret, D. Béchet, and D. Taillandier, "Role of the ubiquitin-proteasome pathway in muscle atrophy in cachexia," Current Opinion in Supportive and Palliative Care, vol. 2, no. 4, pp. 262-266, 2008.

[161] S. H. Lecker, R. T. Jagoe, A. Gilbert et al., "Multiple types of skeletal muscle atrophy involve a common program of changes in gene expression," The FASEB Journal, vol. 18, no. 1, pp. 39-51, 2004.
[162] E. Edstrom, M. Altun, M. Hägglund, and B. Ulfhake, "Atrogin1/MAFbx and MuRF1 are downregulated in aging-related loss of skeletal muscle," The Journals of Gerontology Series A: Biological Sciences and Medical Sciences, vol. 61, no. 7, pp. 663-674, 2006.

[163] M. Sandri, C. Sandri, A. Gilbert et al., "Foxo transcription factors induce the atrophy-related ubiquitin ligase atrogin-1 and cause skeletal muscle atrophy," Cell, vol. 117, no. 3, pp. 399-412, 2004.

[164] P. R. Cao, H. J. Kim, and S. H. Lecker, "Ubiquitin-protein ligases in muscle wasting," The International Journal of Biochemistry \& Cell Biology, vol. 37, no. 10, pp. 2088-2097, 2005.

[165] S. C. Bodine, E. Latres, S. Baumhueter et al., "Identification of ubiquitin ligases required for skeletal muscle atrophy," Science, vol. 294, no. 5547, pp. 1704-1708, 2001.

[166] M. D. Gomes, S. H. Lecker, R. T. Jagoe, A. Navon, and A. L. Goldberg, "Atrogin-1, a muscle-specific F-box protein highly expressed during muscle atrophy," Proceedings of the National Academy of Sciences of the United States of America, vol. 98, no. 25, pp. 14440-14445, 2001.

[167] S. C. Bodine and L. M. Baehr, "Skeletal muscle atrophy and the E3 ubiquitin ligases MuRF1 and MAFbx/atrogin-1," The American Journal of Physiology-Endocrinology and Metabolism, vol. 307, no. 6, pp. E469-E484, 2014.

[168] T. F. Cunha, J. B. N. Moreira, N. A. Paixão et al., "Aerobic exercise training upregulates skeletal muscle calpain and ubiquitinproteasome systems in healthy mice," Journal of Applied Physiology, vol. 112, no. 11, pp. 1839-1846, 2012.

[169] M. Sandri, J. Lin, C. Handschin et al., "PGC-1 $\alpha$ protects skeletal muscle from atrophy by suppressing $\mathrm{FoxO}_{3}$ action and atrophy-specific gene transcription," Proceedings of the National Academy of Sciences of the United States of America, vol. 103, no. 44, pp. 16260-16265, 2006.

[170] D. J. Glass, "Molecular mechanisms modulating muscle mass," Trends in Molecular Medicine, vol. 9, no. 8, pp. 344-350, 2003.

[171] R. Hambrecht, P. C. Schulze, S. Gielen et al., "Effects of exercise training on insulin-like growth factor-I expression in the skeletal muscle of non-cachectic patients with chronic heart failure," European Journal of Cardiovascular Prevention and Rehabilitation, vol. 12, no. 4, pp. 401-406, 2005.

[172] A. Musarò, K. McCullagh, A. Paul et al., "Localized Igf-1 transgene expression sustains hypertrophy and regeneration in senescent skeletal muscle," Nature Genetics, vol. 27, no. 2, pp. 195-200, 2001.

[173] E. R. Barton, L. Morris, A. Musaro, N. Rosenthal, and H. L. Sweeney, "Muscle-specific expression of insulin-like growth factor I counters muscle decline in mdx mice," Journal of Cell Biology, vol. 157, no. 1, pp. 137-147, 2002.

[174] O. Schakman, H. Gilson, V. de Coninck et al., "Insulin-like growth factor-I gene transfer by electroporation prevents skeletal muscle atrophy in glucocorticoid-treated rats," Endocrinology, vol. 146, no. 4, pp. 1789-1797, 2005.

[175] J. E. Stevens-Lapsley, F. Ye, M. Liu et al., "Impact of viralmediated IGF-I gene transfer on skeletal muscle following cast immobilization," American Journal of Physiology: Endocrinology and Metabolism, vol. 299, no. 5, pp. E730-E740, 2010.

[176] P. C. Schulze, J. Fang, K. A. Kassik et al., "Transgenic overexpression of locally acting insulin-like growth factor-1 inhibits ubiquitin-mediated muscle atrophy in chronic left-ventricular dysfunction," Circulation Research, vol. 97, no. 5, pp. 418-426, 2005.

[177] J. Manetta, J. F. Brun, L. Maimoun, A. Callis, C. Préfaut, and J. Mercier, "Effect of training on the GH/IGF-I axis during 
exercise in middle-aged men: relationship to glucose homeostasis," The American Journal of Physiology-Endocrinology and Metabolism, vol. 283, no. 5, pp. E929-E936, 2002.

[178] B. C. Nindl and J. R. Pierce, "Insulin-like growth factor i as a biomarker of health, fitness, and training status," Medicine and Science in Sports and Exercise, vol. 42, no. 1, pp. 39-49, 2010.

[179] R. Hambrecht, P. C. Schulze, S. Gielen et al., "Reduction of insulin-like growth factor-I expression in the skeletal muscle of noncachectic patients with chronic heart failure," Journal of the American College of Cardiology, vol. 39, no. 7, pp. 1175-1181, 2002.

[180] N. G. Mahon, J. B. Young, and W. J. McKenna, "Beta adrenergic blockers in chronic congestive cardiac failure: a call for action," European Journal of Internal Medicine, vol. 13, no. 2, pp. 96-100, 2002.

[181] R. S. Khattar, "Effect of ACE-inhibitors and beta-blockers on left ventricular remodeling in chronic heart failure," Minerva Cardioangiologica, vol. 51, no. 2, pp. 143-154, 2003.

[182] L. D. N. J. De Matos, G. Gardenghi, M. U. P. B. Rondon et al., "Impact of 6 months of therapy with carvedilol on muscle sympathetic nerve activity in heart failure patients," Journal of Cardiac Failure, vol. 10, no. 6, pp. 496-502, 2004.

[183] L. Gullestad, J. Hallen, J. I. Medbø, O. Grønnerød, I. Holme, and O. M. Sejersted, "The effect of acute vs chronic treatment with $\beta$-adrenoceptor blockade on exercise performance, haemodynamic and metabolic parameters in healthy men and women," British Journal of Clinical Pharmacology, vol. 41, no. 1, pp. 57-67, 1996.

[184] M. A. Van Baak, " $\beta$-Adrenoceptor blockade and exercise. An update," Sports Medicine, vol. 5, no. 4, pp. 209-225, 1988.

[185] T. H. Westhoff, N. Franke, S. Schmidt et al., "Beta-blockers do not impair the cardiovascular benefits of endurance training in hypertensives," Journal of Human Hypertension, vol. 21, no. 6, pp. 486-493, 2007.

[186] D. Ladage, R. H. G. Schwinger, and K. Brixius, "Cardio-selective beta-blocker: pharmacological evidence and their influence on exercise capacity," Cardiovascular Therapeutics, vol. 31, no. 2, pp. 76-83, 2013.

[187] L. M. A. B. Van Bortel and M. A. van Baak, "Exercise tolerance with nebivolol and atenolol," Cardiovascular Drugs and Therapy, vol. 6, no. 3, pp. 239-247, 1992.

[188] P. A. Ades, P. G. S. Gunther, W. L. Meyer, T. C. Gibson, J. Maddalena, and T. Orfeo, "Cardiac and skeletal muscle adaptations to training in systemic hypertension and effect of beta blockade (metoprolol or propranolol)," The American Journal of Cardiology, vol. 66, no. 5, pp. 591-596, 1990.

[189] L. Dalla Libera, B. Ravara, V. Gobbo et al., "Skeletal muscle proteins oxidation in chronic right heart failure in rats: can different beta-blockers prevent it to the same degree?" International Journal of Cardiology, vol. 143, no. 2, pp. 192-199, 2010.

[190] M. D. Witham, D. Sumukadas, and M. E. T. Mcmurdo, "ACE inhibitors for sarcopenia-as good as exercise training?" Age and Ageing, vol. 37, no. 4, pp. 363-365, 2008.

[191] A. S. Vanzelli, A. Medeiros, N. Rolim et al., "Integrative effect of carvedilol and aerobic exercise training therapies on improving cardiac contractility and remodeling in heart failure mic," PLOS ONE, vol. 8, no. 5, Article ID e62452, 2013. 


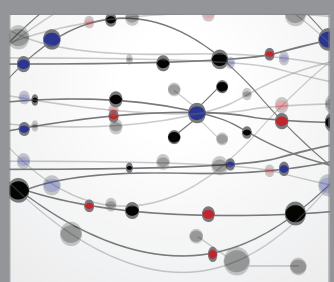

The Scientific World Journal
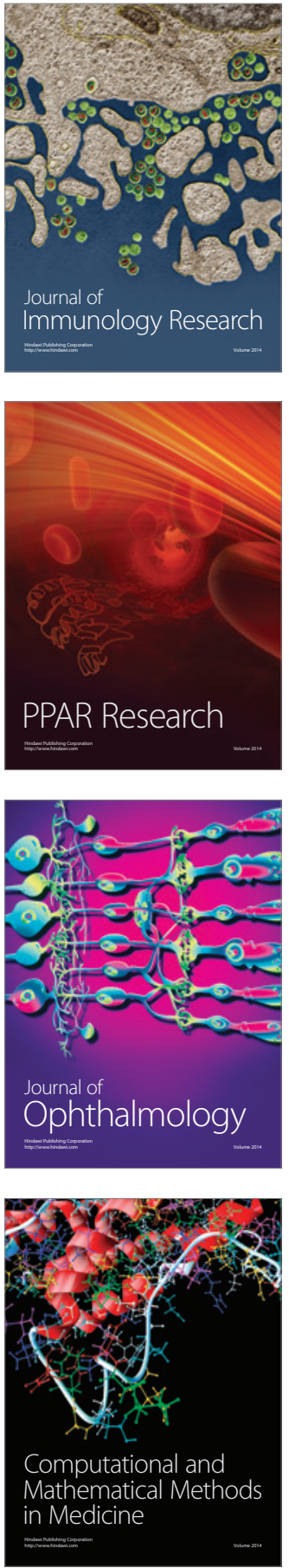

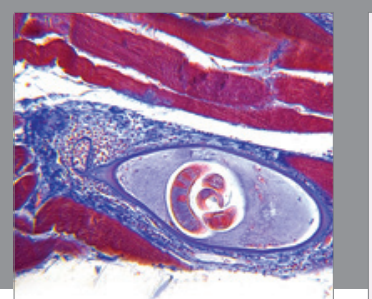

Gastroenterology Research and Practice

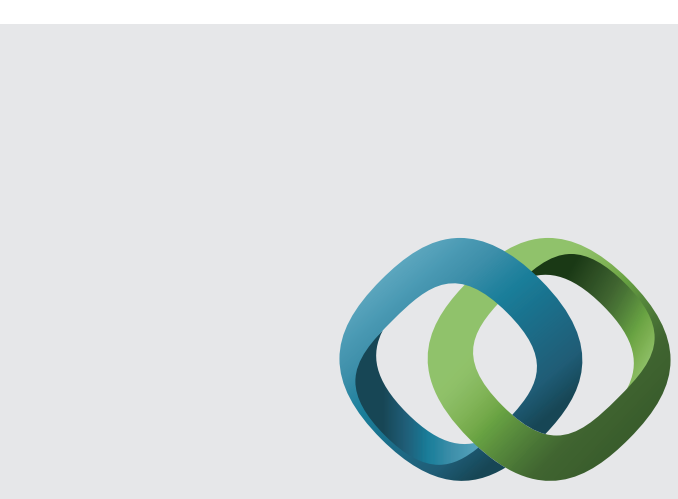

\section{Hindawi}

Submit your manuscripts at

http://www.hindawi.com
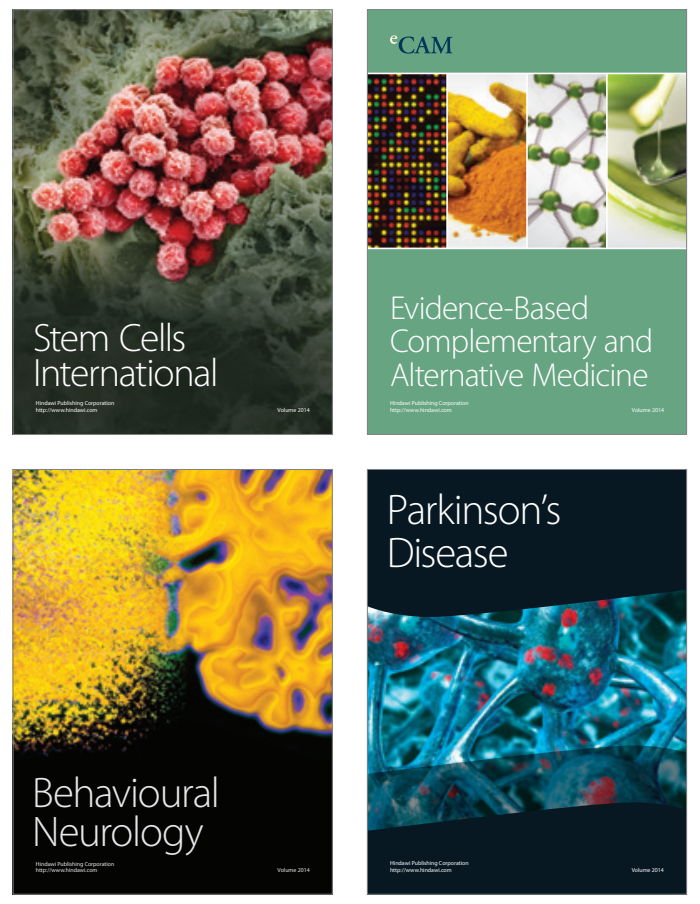
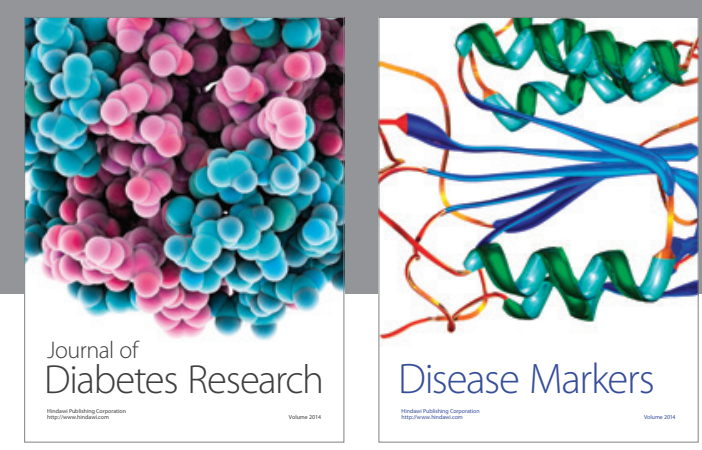

Disease Markers
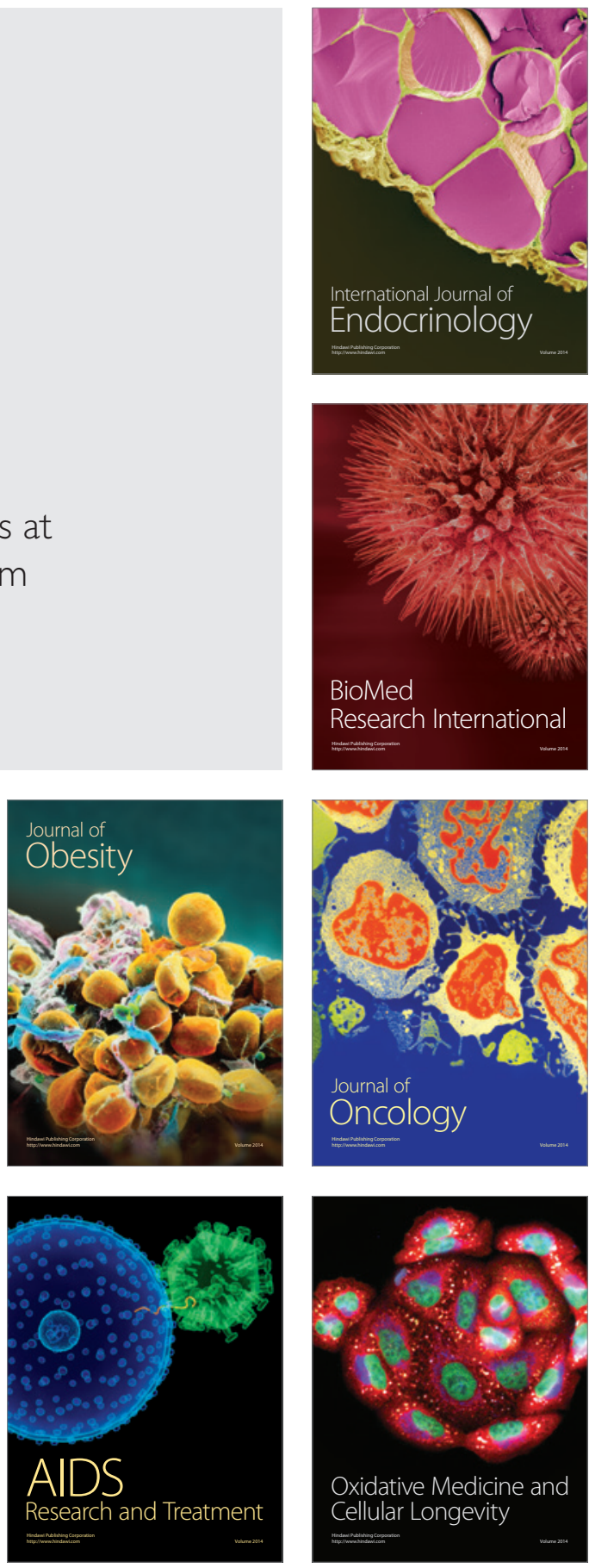